Brightsmith, D. J., J. D. Boyd, E. A. Hobson and C. J. Randel. 2021. Satellite telemetry reveals complex migratory movement patterns of two large macaw species in the western Amazon basin. Avian Conservation and Ecology 16(1):14. https://doi.org/10.5751/ACE-01822-160114 Copyright (C) 2021 by the author(s). Published here under license by the Resilience Alliance.

Research Paper

\title{
Satellite telemetry reveals complex migratory movement patterns of two large macaw species in the western Amazon basin
}

\author{
Donald J. Brightsmith ${ }^{1}$, Janice D. Boyd ${ }^{1}$, Elizabeth A. Hobson ${ }^{2}$ and C J. Randel ${ }^{3}$ \\ ${ }^{1}$ Schubot Avian Health Center, Department of Veterinary Pathobiology, College of Veterinary Medicine and Biomedical Science, \\ Texas A\&M University, ${ }^{2}$ Department of Biological Sciences, University of Cincinnati, Cincinnati, Ohio, USA, ${ }^{3}$ Southwestern \\ Wildlife Survey, South Pasadena, California, USA
}

\begin{abstract}
Understanding avian movement patterns is important to ensure that conservation decisions are made on a scale that is relevant to the species. The family Psittacidae (macaws, parrots and allies) is one of the most endangered large bird families in the world, but due to a variety of technical and logistical difficulties our knowledge of their movements is limited. The scant evidence that exists suggests that parrot populations exhibit a complex mix of migratory and sedentary movement patterns. We obtained location data from 14 Argos satellite transmitter deployments on six Scarlet Macaws (Ara macao) and four Blue-and-yellow Macaws (Ara ararauna) from 2008 to 2016 in lowland tropical moist forest of southeast Peru. The collars provided data spanning $317 \pm 61$ days $(\mathrm{N}$ $=14$ deployments). The data allowed us to document spatial use during the end of the breeding season, the whole non-breeding season, and into the subsequent breeding season. About 30\% of individuals in the study, all marked in 2009, did not show large seasonal changes in spatial use. However, the remaining birds moved up to $150 \mathrm{~km}$ from their nesting areas and averaged a 24-fold increase in range size during the non-breeding season. During the non-breeding season most members of both species engaged in exploratory flights of about $20 \mathrm{~km}$ perhaps to gather information on food availability at the landscape level. Surprisingly, range sizes, range shift timing, and most other movement parameters did not differ between the two macaw species studied. In addition, most individuals of both species moved outside the 1.36 million hectare protected area complex during the non-breeding season, highlighting the need for large protected areas to conserve these macaws in the forests of the western Amazon basin.
\end{abstract}

\section{La télémétrie par satellite révèle des schémas complexes de déplacements migratoires chez deux espèces d'aras de grande taille dans l'ouest du bassin amazonien}

RÉSUMÉ. Les spécialistes chargés de la conservation doivent comprendre les schémas de déplacements des oiseaux pour prendre des décisions à une échelle pertinente pour les espèces. La famille des Psittacidae (aras, perroquets et autres espèces apparentées) est l'une des familles de grands oiseaux les plus menacées au monde, mais notre connaissance de leurs déplacements est limitée en raison de diverses difficultés techniques et logistiques. Les rares données existantes indiquent que les populations de perroquets présentent un mélange complexe de déplacements migratoires et sédentaires. Des données de localisation ont été obtenues à partir de 14 émetteurs satellites Argos déployés sur six Aras rouges (Ara macao) et quatre Aras bleus (Ara ararauna) de 2008 à 2016 dans la forêt tropicale humide de basse altitude du sud-est du Pérou. Les colliers ont fourni des données s'étendant sur $317 \pm 61$ jours $(\mathrm{N}=14)$. Ces données nous ont permis de documenter l'utilisation spatiale à la fin de la saison de nidification, en dehors de la saison de reproduction et pendant la saison de nidification suivante. Pour environ $30 \%$ des individus suivis, tous marqués en 2009 , il n'y a pas eu de grands changements sur le plan de l'utilisation spatiale entre les saisons. Cependant, les autres oiseaux se sont déplacés jusqu'à $150 \mathrm{~km}$ de leur aire de nidification et l'aire occupée en dehors de la saison de reproduction était 24 fois plus grande en moyenne que celle occupée en nidification. En dehors de la saison de reproduction, la plupart des individus des deux espèces ont fait des vols exploratoires d'environ $20 \mathrm{~km}$, peut-être pour sonder la disponibilité de nourriture dans le paysage environnant. Étonnamment, la taille des aires de répartition, le moment du changement d'aires et la plupart des autres paramètres relatifs aux déplacements ne différaient pas entre les deux espèces d'aras étudiées. De plus, la plupart des individus des deux espèces se sont déplacés à l'extérieur du complexe d'aires protégées de 1,36 million d'hectares en dehors de la saison de reproduction, ce qui souligne la nécessité de disposer de grandes aires protégées pour conserver ces aras dans les forêts de l'ouest du bassin amazonien.

Key Words: Argos satellite telemetry; exploratory behavior; home range; protected areas; Psittacidae

\section{INTRODUCTION}

The movement of individual organisms is fundamental to nearly all ecological and evolutionary processes including seed dispersal, metapopulation dynamics, geographic isolation, and more (Nathan 2008, Holland et al. 2009). Knowledge of individual animal movements is also vital for understanding how human impacts like habitat loss, habitat fragmentation, and climate change are impacting species (Møller et al. 2008, Kennedy and Marra 2010). Many conservation efforts are dependent on information about individual movements, especially of migratory

Address of Correspondent: Donald J Brightsmith, Department of Veterinary Pathobiology, TAMU 4467, Texas A\&M University, College Station, TX, USA, brightsmith1@tamu.edu 
animals, to ensure that conservation actions are undertaken in key locations, in appropriate habitats, and at a scale relevant to the needs of the species (Haig et al. 1998, Wright et al. 1999, Allen and Singh 2016, Morellato et al. 2016, Bovo et al. 2018).

The family Psittacidae (macaws, parrots and allies) is one of the most endangered large bird families in the world (Bennett and Owens 1997, Collar 1997, Olah et al. 2016). However, due to a variety of technical and logistical difficulties, our knowledge of parrot movements is limited. They are difficult to capture, and even when captured, the combination of the birds' destructive abilities and their relatively low body mass has made it difficult to create a transmitter that is light enough for the bird to carry, tough enough to resist destruction, and with enough battery life to last through full seasonal migrations (Meyers 1994, Bjork and Powell 1995, Boyd and Brightsmith 2013).

Despite these challenges, we have gained some insight into the seasonal movement patterns of parrots using two lines of evidence: changes in seasonal abundances of parrot populations and VHF (very high frequency) tracking of individual birds. Large drops in abundance post breeding are common at many sites for many species and seasonal appearance of parrots that depart without breeding are regularly recorded in observational studies (Symes and Perrin 2003, Ragusa-Netto 2004, RagusaNetto 2006, McReynolds 2012, Carrara et al. 2019). VHF tracking studies have confirmed that within some species and even within some populations, some individuals remain as sedentary residents while others migrate, and these movements can change from year to year for certain individuals (Snyder et al. 1994, Salinas-Melgoza 2003, Bjork 2004). Other parrot populations show little or no seasonal fluctuation in abundance and radio tracked members show no large-scale seasonal movements suggesting some populations are almost completely resident (Lindsey et al. 1991, Collar 1997, Berg et al. 2007, Lee and Marsden 2012). Often the same species shows marked seasonal fluctuations at some sites and little or no fluctuation at other sites, suggesting highly variable intraspecific movement patterns (Forshaw 1989, Bjork 2004, Karubian et al. 2005, Lee and Marsden 2012). As a whole, these studies suggest that parrots show a complex mix of resident, partially migratory, and fully migratory behaviors and this varies greatly at the level of species and population.

VHF telemetry studies have shown that seasonal movements of 10's of kms (Myers and Vaughan 2004, Salinas-Melgoza and Renton 2007, Ortiz-Maciel et al. 2010) up to 100's of kms (Bjork 2004, Adamek 2011) are regular for medium to large parrots. Most Neotropical parrots have broadly similar diets comprised mostly of plant reproductive parts and landscape level movements are often to exploit variably food supplies resulting from spatial variation in plant community composition and phenological patterns (Salinas-Melgoza and Renton 2007, Gilardi and Toft 2012, Lee et al. 2014, Renton et al. 2015). However, detection distance of VHF collars is limited to just a few $\mathrm{km}$, so tagged birds can only be found in areas where researchers look for them (Enkerlin-Hoeflich 1995, Bridge et al. 2011). As a result, these studies likely underestimate movements, as they are biased against detecting birds at distant and unexpected locations (EnkerlinHoeflich 1995, Bjork 2004, Powell and Bjork 2004, SalinasMelgoza and Renton 2005, Adamek 2011, Faegre and Berkunsky
2014). Due to their complex migration patterns and serious lack of unbiased movement information, studies of psittacine movement are key for better understanding and conserving this highly endangered group.

We use Argos satellite telemetry collars developed for large macaws (Boyd and Brightsmith 2013) to determine the ranging patterns of Scarlet (Ara macao) and Blue-and-yellow (Ara ararauna) Macaws during the breeding and non-breeding seasons in the lowlands of the Tambopata region of southeastern Peru. In this region, both species show large seasonal variation in abundance and soil consumption at clay licks (Renton 2002, Brightsmith et al. 2018). While neither species completely disappears from the area, both species drop greatly in abundance shortly after chicks fledge in March, then abundance increases again during the middle of the dry season beginning in July (Brightsmith et al. 2018, and DJB unpublished data). These apparent fluctuations could be due to changes in detectability (as suggested by Adamek 2011) or long distance movements. VHF telemetry studies by Adamek (2011), based $80 \mathrm{~km}$ from our research site, found that both species expanded their home ranges greatly after breeding, using ranges of $\sim 6,000$ to 27,000 ha. Based on these observations, we hypothesized that: 1) migratory macaws will have home ranges of thousands of ha during the non-breeding season and 2) both species will be partially migratory, with some individuals remaining at the site year-round while others migrate away from the breeding grounds.

\section{METHODS}

\section{Study area}

Our study site was the Tambopata Research Center (13 $08^{\prime} \mathrm{S}, 69^{\circ}$ $36^{\prime}$ W) in Madre de Dios Department in southeastern Peru. The center is located in the Tambopata National Reserve (275,000 ha) immediately adjacent to the Bahuaja-Sonene National Park $(1,091,000 \mathrm{ha})$. The area is tropical moist forest near the boundary with subtropical wet forest (Tosi 1960) and both protected areas remain almost completely covered with native vegetation. The elevation is $250 \mathrm{~m}$ asl with $3,200 \mathrm{~mm}$ of rain per year and a wet season from November to March (Brightsmith 2004). The area contains a mix of mature floodplain forest, successional floodplain forest, Mauritia flexuosa palm swamps, and upland forest (Foster et al. 1994). The site is adjacent to the large Colorado Clay Lick, where psittacines and other birds and mammals consume sodium-rich clay on a daily basis (Brightsmith 2004, Brightsmith and Villalobos 2011).

\section{Macaw capture and device attachment}

We captured 14 separate individual macaws (Scarlet $=8$, Blueand-yellow $=6$ ) and deployed on them 18 PTT collars over a total of seven field seasons between 2008 and 2016. Four collars failed shortly after deployment and did not give enough data to be included in the study so we report data on 14 deployments across 10 total macaws (Scarlet $=6$, Blue-and-yellow $=4$ ). We obtained data from two Scarlet Macaws in more than one season: Angeles in four different seasons and Franz in two different seasons. All other macaws were collared only once. All macaws trapped were adults. Macaws were trapped in two different types of sites, the Colorado Clay Lick ( $\mathrm{N}=9$ individuals and 9 collar deployments on 6 Blue-and-yellow and 3 Scarlet Macaws during Jan - Feb 2008, 
Jan, Feb, and Dec 2009) or at active nests ( $\mathrm{N}=5$ individuals all Scarlet Macaws, Jan - Feb 2011, 2012, 2013, 2016, some of which were retrapped multiple times at the same nest or at nest sites within $1 \mathrm{~km}$, resulting in 11 different collar deployments). At the clay lick we used two different trapping methods: a modified balchatri trap where nylon loops were tied to perches adjacent to clay licks ( $\mathrm{N}=6$ captured individuals) or mist nets adjacent to clay licks ( $\mathrm{N}=3$ individuals). The artificial nests used for trapping were hung as part of our macaw breeding ecology studies (Nycander et al. 1995, Vigo et al. 2011, Olah et al. 2014). We trapped macaws at active nests only after they had large chicks (> 40 days old) which were able to thermoregulate on their own. Further details of the trapping methods are not presented here to guard against others using them for poaching or other nonscientific purposes.

In all nests we attempted to capture the males. Sex identification of individuals at target nests was done during hundreds of hours of observations during a companion study (Vigo Trauco 2020). We identified the sex of all captured birds as male if they were observed feeding females. (Vigo Trauco 2020). However, in one nest (Ceiba), the bird captured and radio collared was the female (Gabriela Vigo and DJB unpublished data). In an effort to determine if movement patterns by individual birds were consistent among years, two birds were retrapped at nests in subsequent years and given new collars: Angeles ( $\mathrm{N}=4$ seasons) and Franz ( $\mathrm{N}=2$ seasons).

We fitted macaws with either North Star Science and Technology (32 g, 2008-2009, custom built model) or Telonics (37 g model TAV-2627, 2009-2016) low power (250 mW) Argos platform terminal transmitters (PTTs; heretofore referred to as "collars", Boyd and Brightsmith 2013). This satellite-based system uses Doppler shifts in pulsed radio frequencies to locate transmitters anywhere in the world, eliminating the spatial bias inherent in many VHF studies (Bridge et al. 2011). Both collars were of similar design, having PTT electronics canisters attached via a narrow metal band around the bird's neck, allowing the electronics canister to hang below the beak roughly at crop level. An approximately $21 \mathrm{~cm}$ long antenna extended from the canister along the metal neck band to the back of the collar. The total transmitter mass of both models was about 3-4\% of the total body mass of the bird, as most study birds weighed slightly over $1 \mathrm{~kg}$ (Dunning 2008 and Brightsmith unpublished data). The two collars had similar location accuracy (Boyd and Brightsmith 2013). In the Telonics collars, neckbands were attached by screwing them into the body of the electronics canister using a screw and rustable washer. Rustable materials were used in the hopes that the collar would fall off in a year or more. To facilitate rusting, galvanized washers were soaking in dilute hydrochloric acid to remove the zinc.

The objective of the study was to obtain ranging patterns during the non-breeding season. For this reason, we programmed our collars to broadcast for a total of 6-8 hours during daylight hours, every 3-6 days to spread the manufacturer's estimated 400 transmission hours across the January to October period of minimum macaw abundance at our site. During broadcast, collars transmitted once every minute. These transmissions were only received and processed when a satellite was overhead, and satellites used the information from multiple transmissions to calculate one location per overflight. This system normally produced < 4 locations per day. In 2008 and 2009 we programmed collars to broadcast for a single 8- or 11-hour block per broadcast day. In subsequent years, we used the Telonics Product Programmer to predict times of high satellite availability and programmed collars to broadcast in two blocks of about $4 \mathrm{hrs}$ per broadcast day to overlap times of high satellite availability (Telonics 2015). For all Blue-and-yellow Macaws and all but one Scarlet Macaw, over $99.5 \%$ of all locations were obtained between 06:00 and 18:00 (daylight hours). For one Scarlet Macaw (Wheezy) all locations were obtained between 13:00 and 22:00 likely due to user error in programming or starting the transmitter.

\section{Data processing}

Data were downloaded from Argos-Web and consolidated into Excel files for later analysis. Using the provided location codes, we selected location data with estimated lognormal mean error of $\sim 2 \mathrm{~km}$ or less for inclusion in our analyses (Boyd and Brightsmith 2013). We implemented quality control procedures to identify and remove duplicate locations and outliers. We identified outliers as sequential points separated by a distance of $>6 \mathrm{~km}$ where the distance and time between the locations suggested that the bird would have had to move at a speed of $>$ $50 \mathrm{~km}$ per hour to arrive at the second point. We used $6 \mathrm{~km}$ as a cutoff because mean errors for our points were near $2 \mathrm{~km} \pm 1.5$ $\mathrm{km}$; we used the $50 \mathrm{~km}$ per hour cutoff based on GPS transmitter data from our site indicating macaws normally travel at about 40 $\mathrm{km}$ per hour during long distance flights (DJB unpublished data).

We parsed our location data into two categories: breeding season and non-breeding season. Because breeding seasonality of parrots is highly variable among species and within species across the range (Roth 1984, Brightsmith 2005), and because there was no previous information on seasonal movements of our populations, we were unable to provide a priori definitions for these seasons. Instead we did a post hoc examination of the data and found that most of the birds showed major seasonal shifts in ranges in March or April. These major seasonal shifts in ranges all began with a single movement of $>10 \mathrm{~km}$ away from the breeding range. As a result, we used an absolute displacement method (first movement $>10 \mathrm{~km}$ from the breeding range) to define the end of the breeding season and the onset of migration (see Soriano-Redondo et al. 2020 for more on methods of determining timing of migrations). We defined the start of the non-breeding season as the first locations following the first movement away from the breeding range and the end of the nonbreeding range when the individual returned to the breeding range for the last time in anticipation of breeding (late August \pm 1 month). For individuals that did not show seasonal movements we used the average beginning and end dates for the non-breeding season for that species to define the breeding and non-breeding season. This was done to allow us to create comparable seasonal ranges for comparing between migratory and non-migratory individuals.

\section{Home range calculation}

We calculated individual macaw home ranges using 100\% minimum convex polygons (MCPs) and 70\% isopleth fixed kernel density estimators (KDE, Warton 1989, Kie et al. 2010). We calculated $50 \%$ and $70 \%$ isopleths but found that the $50 \%$ were 
small and fragmented and did not coalesce in to reasonable core areas. Macaw use of the landscape showed clear temporal autocorrelation as the birds spent a great deal of time around their nests on most days and often moved sequentially through the core area sections of their non-breeding ranges (Figures A2.1 to A2.14). A preliminary analysis which suggested that individual sections of the non-breeding core areas used by macaws averaged around $212 \pm 188 \mathrm{~km}^{2}$ (28 core area sections among the 11 home ranges analyzed) and that sequential locations (regardless of time difference) averaged about $4 \pm 8 \mathrm{~km}$ apart. Given that macaws at our site are known to fly at speeds of around $40 \mathrm{~km}$ per hour (DJB unpublished data from GPS telemetry collars), this suggests that macaws could reach most points within a core area section within about 30 minutes. To reduce the effect of temporally autocorrelated location data and to better calculate the $70 \% \mathrm{KDE}$ range estimate, we used these results to exclude some of the locations in our dataset: we omitted all sequential points separated by $<30$ minutes and $<4 \mathrm{~km}$. This method eliminated locations collected within a short time span if individuals were not moving around very much and eliminated 13\% of the locations for Scarlet Macaws and 12\% for Blue-and-yellow Macaws. We used all locations for the MCP ranges as these are not impacted by temporal autocorrelation.

We calculated both MCP and KDE ranges for the breeding season, non-breeding season, and annual home ranges for all individual deployments. For birds tracked in multiple years, home ranges were calculated for each deployment (i.e., each year the bird was collared). Both MCP and KDE ranges were calculated in the Geospatial Modeling Environment (Beyer 2012) using the 'genmcp' and 'kde' tools, respectively. We used MCPs to provide conservative estimates of the total area covered by each marked bird and total area covered by each species during our study. We selected the $70 \% \mathrm{KDE}$ isopleth to quantify the core areas use intensity by individual macaws for both annual and seasonal ranges. We refer to these $70 \% \mathrm{KDE}$ as core areas for the remainder of the paper. All KDE ranges were estimated for analysis periods (breeding or non-breeding) with $\geq 30$ locations.

\section{Data analysis}

We successfully tracked a total of 10 individual birds: 4 Blue-andyellow Macaws and 6 Scarlet Macaws. Of these, two Scarlet Macaws were tracked in more than one season resulting in a total of 14 deployments over 10 birds. For between season comparisons, we analyzed data paired by individual at the level of deployments for each macaw species. However, for home range comparisons between the two species we ran statistical analyses at the level of the individual. For these analyses we calculated the average value across years for each parameter for the two individuals that received deployments in multiple years and used these averages in the analyses. This was done because our data included repeated deployments on two individual Scarlet Macaws but did not have repeat deployments for Blue-and-yellow Macaws.

Data were checked for normality using normal quantile plots. To test for differences in home range sizes between species, we used Wilcoxon rank-sum test with p-values generated using the 1-way $\chi^{2}$ approximation for data that were not normally distributed and t-tests assuming equal variance for normally distributed data. To test for differences between ranges used during the breeding and non-breeding seasons within each deployment, we used a paired t-test for normally distributed data and a Wilcoxon signed-rank test for data that were not normally distributed. To determine if the sections of the non-breeding $70 \% \mathrm{KDE}$ ranges closer to the nest received more distinct visits than such areas further from the nests during the non-breeding season, we conducted two least square regression tests, one with $\log 10$ (number of visits) and the other with $\log 10$ (number of dates recorded) as independent variables, with distance from the nest as independent variable and individual as a random factor.

The number of locations we obtained per day was constrained by our need to broadcast only 6 to 8 hours per day to make the limited battery life last from January to October. This precluded us from calculating total daily movements (see Results: Daily movements for details on locations per day). However, given that there is little published information on minimum movements by these species, we used our data to provide a rough minimum estimate of daily movement. Here we report an "index of daily movement" calculated as the sum of the distances between subsequent locations on the same day for the same individual. These movements could only be calculated on days when individual birds had two or more locations. To test for differences in the maximum index of daily movement for individuals between species, we used a Wilcoxon rank-sum test as data were not normally distributed. To determine if our index of daily movement differed between the breeding and non-breeding season within species, we ran a least squares regression with daily movement index as the dependent variable, season as the independent variable, and number of locations per day and bird as random effects. To determine if daily movement differed between species, we ran a similar least squares regression with species as the independent variable. Since total daily movement index is greater with larger numbers of locations, we tested for differences in the mean number of locations per day between species using a Wilcoxon rank-sum test as locations per day were not normally distributed for Blue-and-yellow Macaws.

To determine if the number of dates on which the birds returned to and were recorded inside the breeding range during the nonbreeding season varied between species we used a Wilcoxon ranksum as data were not normally distributed. To test if the nonbreeding ranges of the two species lay in different directions from their breeding ranges we calculated the azimuth from the nest to the furthest point in the non-breeding MCP range for Scarlet Macaws and the azimuth from the center of the breeding range to the furthest point in the non-breeding MCP range for Blueand-yellow Macaws. We compared the resulting azimuths using a Wilcoxon rank-sum test as data did not follow a normal distribution.

To test the intra-individual variability for Scarlet Macaw spatial use among years, we calculated the percent annual overlap in the MCP home ranges between years for the individuals that were tracked during more than one year. This was calculated at the percentage of year $1 \mathrm{MCP}$ that overlapped all subsequent year ranges, the percent of the year 2 range that overlapped year 1 range and all subsequent year ranges etc. This resulted in 14 overlap values for each of the home range types for the repeat collared birds: Angeles ( $\mathrm{N}=4$ years, $\mathrm{N}=12$ overlap values) and Frans $(\mathrm{N}=2$ years, $\mathrm{N}=2$ overlap value). The percent overlap of 
Table 1. Minimum convex polygon (MCP) home ranges for Scarlet Macaws (SCMA) and Blue-and-yellow Macaws (BYMA) in the lowlands of southeastern Peru. "Year" shows the year in which the collar was deployed. Migratory = 1 denotes birds that showed a major spatial shift between their breeding and non-breeding ranges. The "Annual" ranges span the entire time the collar was active even though this was not always 12 months or more. All areas are given in $\mathrm{km}^{2}$. The $\mathrm{N}$ for each is the number of locations included in the calculations. The $\mathrm{P}$ values were calculated with a Wilcoxon rank-sum test between the two species. The average values for Angeles and Franz were used in the calculation of individual based data for Scarlet Macaws.

\begin{tabular}{|c|c|c|c|c|c|c|c|c|c|}
\hline \multirow[b]{2}{*}{ Name } & \multirow[b]{2}{*}{ Year } & \multirow[b]{2}{*}{ Species } & \multirow[b]{2}{*}{ Migratory } & \multicolumn{2}{|c|}{ Breeding } & \multicolumn{2}{|c|}{ Non-breeding } & \multicolumn{2}{|c|}{ Annual } \\
\hline & & & & Area & $\mathrm{N}$ & Area & $\mathrm{N}$ & Area & $\mathrm{N}$ \\
\hline Angeles & 2011 & SCMA & 1 & 158 & 180 & 3565 & 100 & 4953 & 280 \\
\hline Angeles & 2012 & SCMA & 1 & 145 & 91 & 1968 & 76 & 2160 & 167 \\
\hline Angeles & 2013 & SCMA & 1 & 94 & 180 & 5647 & 205 & 5647 & 385 \\
\hline Angeles & 2016 & SCMA & 1 & 35 & 102 & 715 & 148 & 715 & 251 \\
\hline Ceiba & 2012 & SCMA & 1 & 53 & 69 & 1576 & 150 & 1741 & 219 \\
\hline Franz & 2012 & SCMA & 1 & 183 & 222 & 582 & 139 & 598 & 361 \\
\hline Franz & 2013 & SCMA & 1 & 99 & 67 & 1761 & 143 & 1761 & 210 \\
\hline Hugo & 2013 & SCMA & 1 & 181 & 170 & 703 & 182 & 729 & 359 \\
\hline DanyE & 2009 & SCMA & 0 & 282 & 212 & 216 & 202 & 419 & 414 \\
\hline Wheezy & 2009 & SCMA & 0 & 170 & 62 & 84 & 121 & 227 & 183 \\
\hline \multicolumn{4}{|c|}{ SCMA by deployment (Mean \pm Stdev) } & $140 \pm 72$ & $135 \pm 63$ & $1681 \pm 1737$ & $146 \pm 41$ & $1895 \pm 1912$ & $282 \pm 90$ \\
\hline \multicolumn{4}{|c|}{ SCMA by individual } & $156 \pm 77$ & $132 \pm 58$ & $1121 \pm 1069$ & $155 \pm 31$ & $1277 \pm 1161$ & $288 \pm 86$ \\
\hline Charming & 2010 & BYMA & 1 & 37 & 71 & 2900 & 247 & 3143 & 318 \\
\hline Libertad & 2008 & BYMA & 1 & 143 & 240 & 2377 & 97 & 2436 & 337 \\
\hline Tiny & 2008 & BYMA & 1 & 134 & 40 & 453 & 47 & 1592 & 87 \\
\hline Fuga & 2009 & BYMA & 0 & 293 & 70 & 259 & 16 & 353 & 86 \\
\hline \multicolumn{4}{|c|}{ BYMA $($ Mean \pm Stdev $)$} & $151 \pm 105$ & $105 \pm 90$ & $1497 \pm 1337$ & $101 \pm 102$ & $1881 \pm 1199$ & $207 \pm 139$ \\
\hline \multicolumn{4}{|c|}{ Species comparison individuals ( $\mathrm{P}$ value) } & $0.9 \dagger$ & $0.7 \ddagger$ & $0.8 \ddagger$ & $0.2 \ddagger$ & $0.5 \ddagger$ & $0.4 \$$ \\
\hline
\end{tabular}

all other pairs of home ranges for all other birds were also calculated ( $\mathrm{N}=5$ birds, $\mathrm{N}=20$ overlap values). These percent overlap values were arcsine transformed to normalize the data and tested using a two-sample t-test. No individual Blue-andyellow Macaws were tracked in multiple years so we could only estimate intra-individual variability for Scarlet Macaws.

All statistical tests were conducted either in JMP pro v15.0.0 JMP (SAS Institute 2019) or in R using alpha $=0.05$. Data are presented as mean \pm standard deviation unless otherwise noted.

\section{RESULTS}

We obtained $261 \pm 106$ locations per deployment on $70 \pm 15$ distinct dates spanning $317 \pm 61$ days ( $\mathrm{N}=14$ deployments) for a total of 3,657 usable locations and about 147 months of useful data across six Scarlet and four Blue-and-yellow Macaws. (Table A1.1).

We identified two major movement patterns: birds that made large seasonal movements and those that did not. All three birds captured at the clay lick and tracked in 2009 (two Scarlet Macaws and one Blue-and-yellow Macaw) had relatively small annual MCP home ranges (227, 419 and $353 \mathrm{~km}^{2}$ respectively, Table 1) with little difference between breeding and non-breeding season ranges (Table 1, Figures A2.1, A2.2). The remaining 7 birds of both species (captured at nests and clay licks and tracked in all other years) showed clear differences in size and location between their breeding and non-breeding season ranges. All of the Scarlet Macaws with known nests showed major range shifts but the breeding status of the Blue-and-yellow Macaws was unknown as they were all trapped at the clay lick.

\section{Home ranges and core areas}

$M C P$ home ranges

The entire area ranged over by our 10 macaws was $21,150 \mathrm{~km}^{2}$ (MCP home range for all 10 birds over 14 deployments). Scarlet Macaw annual MCP ranges were $1,227 \pm 1161 \mathrm{~km}^{2}(\mathrm{~N}=6$ individuals, Fig. 1). Blue-and-yellow Macaw annual MCP ranges were $1,881 \pm 1,199 \mathrm{~km}^{2}(\mathrm{~N}=4$ individuals, Fig. 1). These average annual range sizes for the two species did not differ significantly (Table 1).

In both the breeding and non-breeding seasons, the two macaw species did not differ significantly in the size of the MCP home ranges (Table 1). Breeding MCP home ranges for both species combined averaged $154 \pm 84 \mathrm{~km}^{2}(\mathrm{~N}=10$ individuals). During the non-breeding season, MCP home ranges for both species combined averaged $1271 \pm 1126 \mathrm{~km}^{2}(\mathrm{~N}=10$ individuals $)$. Considering only migratory individuals, Scarlet Macaw nonbreeding MCP ranges $\left(1606 \pm 979 \mathrm{~km}^{2}, \mathrm{n}=4\right.$ individuals $)$ did not differ significantly in size from those of the Blue-and-yellow Macaw $\left(1910 \pm 1288 \mathrm{~km}^{2}, \mathrm{n}=3\right.$ individuals, Wilcoxon rank-sum: $\left.\chi^{2}=0, \mathrm{df}=1, \mathrm{P}=1.0\right)$. For the birds of both species that migrated during their deployments, the non-breeding ranges (2022 \pm 1571 $\mathrm{km}^{2}$ ) were almost 18 times larger than the breeding ranges (115 $\pm 55 \mathrm{~km}^{2}$ ) and this difference was highly significant (paired t-test: $\mathrm{t}=4.0, \mathrm{df}=10, \mathrm{P}=0.0025)$. The three birds from 2009 which did not migrate showed a different pattern: the breeding season ranges ( $248 \pm 68 \mathrm{~km}^{2}, \mathrm{~N}=3$ ) were slightly larger than the non-breeding ranges but the difference was not significant $\left(186 \pm 91 \mathrm{~km}^{2}, \mathrm{~N}=\right.$ 3 , Wilcoxon signed-rank: $\mathrm{S}=-3.0, \mathrm{P}=0.25$ ). 
Fig. 1. Annual minimum convex polygon home ranges of Scarlet and Blue-and-yellow Macaws. Ranges are shown for 10 Scarlet Macaw deployments (6 individuals) and 4 Blue-andyellow Macaws (1 deployment per individual). The protected areas (Tambopata National Reserve, Bahuaja Sonene National Park, and Madidi National Park) are shown in light green. Puerto Maldonado is the departmental capital and the largest city in the area. All birds were trapped within a $1 \mathrm{~km}$ radius of the Tambopata Research Center which is shown by the star.

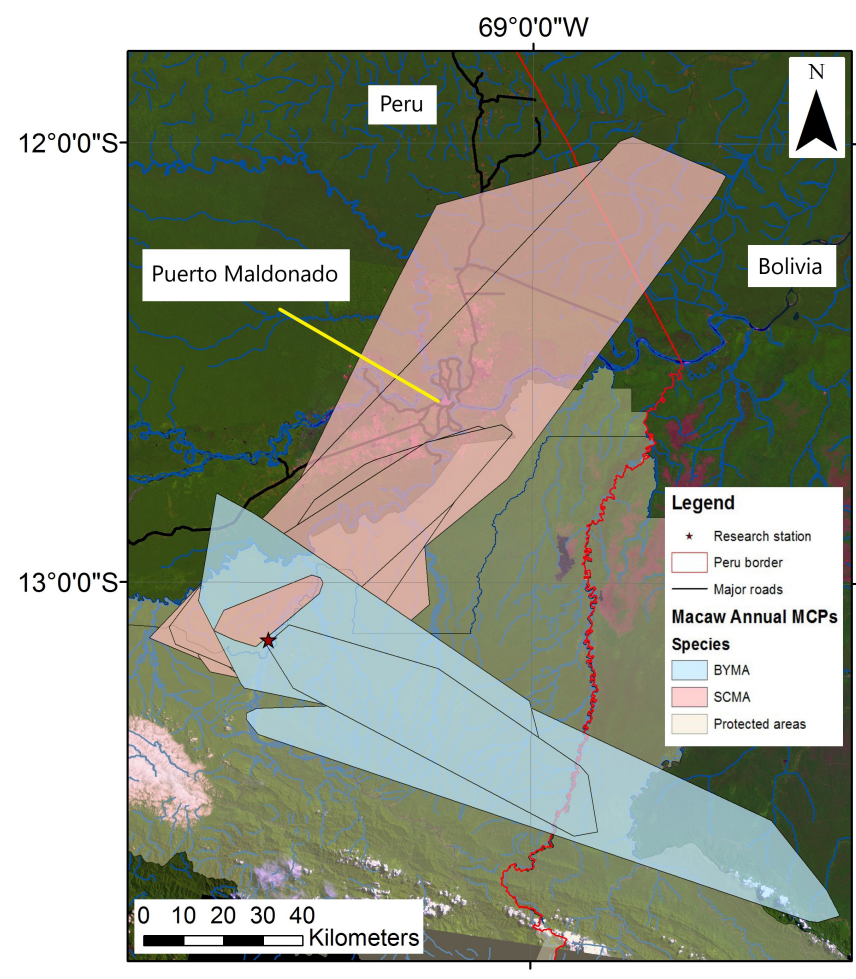

\section{Core areas}

Breeding core areas ( $70 \% \mathrm{KDE}$ ranges) for both species combined averaged $111 \pm 198 \mathrm{~km}^{2}(\mathrm{~N}=10$ individuals, Table 2). Blue-andyellow Macaw breeding core areas were almost five times larger than those of Scarlet Macaws, but this difference was not statistically significant (Table 2). When looking only at the Scarlet Macaws which had active nests, the breeding season core areas averaged $54 \pm 37 \mathrm{~km}^{2}(\mathrm{~N}=4$ individuals $)$.

During the non-breeding season, core areas for both species combined averaged $334 \pm 273 \mathrm{~km}^{2}(\mathrm{~N}=9$ individuals, Table 2). Non-breeding core areas did not differ significantly between species (Table 2). Considering only birds that migrated during their deployments, the difference between species for nonbreeding core areas was also not significant (Wilcoxon rank-sum: $\chi^{2}=1.1$, df $=1, P=0.3$ ).

For the birds that migrated during their deployments, the nonbreeding core areas ( $448 \pm 264 \mathrm{~km}^{2}, \mathrm{~N}=6$ individuals) averaged three times larger than the breeding core areas $\left(149 \pm 256 \mathrm{~km}^{2}, \mathrm{~N}\right.$ $=6$ individuals) and this difference was significant (Wilcoxon signed-rank: $\mathrm{S}=10.5, \mathrm{P}=0.03$ ). For the three birds from 2009 that did not migrate, the non-breeding core areas $\left(107 \pm 90 \mathrm{~km}^{2}\right.$, $\mathrm{N}=3)$ and the breeding season core areas $\left(52 \pm 47 \mathrm{~km}^{2}, \mathrm{~N}=3\right)$ did not differ significantly (Paired t-test: $\mathrm{t}=1.69, \mathrm{df}=2, \mathrm{P}=0.5$ ).

For five of the eight Scarlet Macaw deployments (3 individuals), the non-breeding core areas $(70 \% \mathrm{KDE})$ contained the nest but for the other three deployments it did not (two individuals, Figures A2.3 to A2.10). For Angeles, the non-breeding core areas included the nest in two deployments and did not include it in two deployments (Figures A2.3 to A2.4). Of the three Blue-andyellow Macaws that showed seasonal movements, none had nonbreeding cores area that included the center of the breeding range (Figures A2.12 to A2.14).

\section{Movements among core areas}

The non-breeding 70\% KDE ranges for the Scarlet Macaws that migrated had $3.0 \pm 0.5$ disjunct sections (Figure A2.3 to A2.10), suggesting the birds used a variety of spatially distinct core areas during this season. Centers of the distinct core area sections averaged $44.5 \pm 44.9 \mathrm{~km}$ from the nests (range $=3$ to $151 \mathrm{~km}, \mathrm{~N}$ $=24$ disjunct sections across 8 deployments on 4 birds).

On average, core area sections further from the nest sites received less distinct visits than those that were closer to the nests (least squares regression on $\log 10$ (number of visits): $\mathrm{R}^{2}=0.41, \mathrm{t}$ ratio $=-3.37$, DF 21.3, $\mathrm{P}=0.0028$ ). For example, all core area sections over $70 \mathrm{~km}$ from the nest were visited only once, for an average of $23 \pm 21$ days $(\mathrm{N}=6$ distinct core areas). These results, along with the detailed movements of the individual birds (Figs. A2.1 to A2.8), suggest that when Scarlet Macaws were far from the nest in the non-breeding season, they tended to remain in fairly small areas for a period of a few days to a few weeks. After leaving this small area, they would rarely return to it. Instead, they would move on to another relatively small area and stay there for a similar period of time. This pattern usually repeated until the birds returned to the breeding range.

However, the total number of dates on which birds were recorded in different core area sections (an index of time spent in each section) did not vary with distance from the nest (least squares regression on $\log 10$ [number of dates in each core area]: $\mathbf{R}^{2}=0.01$, $\mathrm{t}$ ratio $=-1.51$, DF $12.33, \mathrm{P}=0.16$ ). This suggests that the total amount of time the birds spent in each core area was rather similar regardless of the distance from the nest. This pattern was produced because, when macaws were near their nests during both the breeding and non-breeding season, they would repeatedly move among different areas visiting them frequently and visiting the same patch repeatedly on multiple different days.

These patterns of movement among core areas in the nonbreeding season for Scarlet Macaws were not found for the three migratory Blue-and-yellow Macaws, as all non-breeding core areas for Blue-and-yellow Macaws were visited only once or twice regardless of distance from the breeding season range (Figure A2.12 to A2.14).

\section{Daily movements}

We recorded $3.6 \pm 1.9$ locations per day for each bird $(\mathrm{N}=1008$ days with $\geq 1$ location), suggesting that our daily movement indices captured only a fraction of total daily movement. However, due to the paucity of movement data for these species 
Table 2. Core area range sizes for Scarlet Macaws (SCMA) and Blue-and-yellow Macaws (BYMA) in the lowlands of southeastern Peru. The ranges were calculated using 70\% kernel density estimates. "Year" shows the year in which the collar was deployed. Migratory $=1$ denotes birds that showed a major spatial shift between their breeding and non-breeding ranges. All areas are given in $\mathrm{km}^{2}$. The $\mathrm{N}$ for each is the number of locations included in the calculations. This number is lower than the corresponding values for the MCP home ranges (Table 1) because all locations within 30 minutes and $4 \mathrm{~km}$ were eliminated to reduce spatiotemporal autocorrelation (see Methods for further discussion). The $\mathrm{P}$ values were calculated with a Wilcoxon rank-sum test comparing the two species. The average values for Angeles and Franz were used in the calculation of individual based data for Scarlet Macaws.

\begin{tabular}{|c|c|c|c|c|c|c|c|}
\hline \multirow[b]{2}{*}{ Name } & \multirow[b]{2}{*}{ Year } & \multirow[b]{2}{*}{ Species } & \multirow[b]{2}{*}{ Migratory } & \multicolumn{2}{|c|}{ Breeding } & \multicolumn{2}{|c|}{ Non-breeding } \\
\hline & & & & Area & $\mathrm{N}$ & Area & $\mathrm{N}$ \\
\hline Angeles & 2011 & SCMA & 1 & 17 & 160 & 1196 & 82 \\
\hline Angeles & 2012 & SCMA & 1 & 397 & 84 & 506 & 70 \\
\hline Angeles & 2013 & SCMA & 1 & 14 & 156 & 1311 & 164 \\
\hline Angeles & 2016 & SCMA & 1 & 7 & 86 & 187 & 117 \\
\hline Ceiba & 2012 & SCMA & 1 & 36 & 63 & 335 & 134 \\
\hline Franz & 2012 & SCMA & 1 & 55 & 184 & 197 & 123 \\
\hline Franz & 2013 & SCMA & 1 & 28 & 62 & 641 & 122 \\
\hline Hugo & 2013 & SCMA & 1 & 29 & 150 & 258 & 164 \\
\hline DanyE & 2009 & SCMA & 0 & 17 & 184 & 95 & 176 \\
\hline Wheezy & 2009 & SCMA & 0 & 34 & 50 & 24 & 105 \\
\hline \multicolumn{4}{|c|}{ SCMA by deployment (Mean \pm Stdev) } & $63 \pm 118$ & $117 \pm 53$ & $475 \pm 449$ & $125 \pm 35$ \\
\hline \multicolumn{4}{|c|}{ SCMA by individual } & $44 \pm 33$ & $115 \pm 51$ & $322 \pm 277$ & $135 \pm 29$ \\
\hline Charming & 2010 & BYMA & 1 & 12 & 66 & 143 & 200 \\
\hline Libertad & 2008 & BYMA & 1 & 668 & 217 & 733 & 85 \\
\hline Tiny & 2008 & BYMA & 1 & 64 & 37 & $\dagger$ & 44 \\
\hline Fuga & 2009 & BYMA & 0 & 106 & 68 & 202 & 15 \\
\hline \multicolumn{4}{|c|}{ BYMA (Mean \pm Stdev) } & $212 \pm 305$ & $97 \pm 81$ & $359 \pm 324$ & $86 \pm 81$ \\
\hline \multicolumn{4}{|c|}{ Species comparison individuals ( $\mathrm{P}$ value) } & $0.4^{\ddagger}$ & $0.7^{\dagger}$ & $1.0^{\ddagger}$ & $0.2^{*}$ \\
\hline
\end{tabular}

we present a comparison of our daily movement indices between seasons and species. The maximum daily movement indices we recorded for individual Scarlet Macaws averaged $40.7 \pm 22.1 \mathrm{~km}$ (range $=16.7-81.5 \mathrm{~km}, \mathrm{~N}=6$ individuals). The maximum daily movement indices for Blue-and-yellow Macaws averaged 21.6 $\pm 10.4 \mathrm{~km}$ (range $=13.8-36.7 \mathrm{~km}, \mathrm{~N}=4$ birds). Although the maximum daily movements of the Scarlet Macaws was double that of Blue-and-yellow, this difference was not statistically significant (Wilcoxon rank-sum: $\chi^{2}=3, \mathrm{DF}=1, \mathrm{P}=0.13$ ). However, the mean number of locations per day was significantly greater for Scarlet Macaws $(3.9 \pm 1.8, \mathrm{~N}=731$ days with $2 \geq$ location) than for Blue-and-yellow Macaws (3.0 $\pm 1.9, \mathrm{~N}=277$ days with $1 \geq=$ location, Wilcoxon rank-sum: $\chi^{2}=91.8, \mathrm{DF}=1$, $\mathrm{P}<0.0001)$.

Our estimates of daily movements for Scarlet Macaws that migrated were significantly greater during the non-breeding season $(12.9 \pm 10.0)$ than during the breeding season $(8.9 \pm 6.6)$ after accounting for the variation in number of locations per day and individual (Table 3). The two Scarlet Macaws from 2009 that did not migrate during their deployments did not differ in their daily movements between seasons (Table 3). Unlike Scarlet Macaws, the estimates of daily movements for the three Blue-andyellow Macaws that migrated were not significantly greater during the non-breeding season (Table 3). Surprisingly, the one Blue-andyellow Macaw from 2009 that did not migrate moved significantly less during the non-breeding season than during the breeding season (Table 3).

Scarlet Macaws that migrated had an average daily movement index during the non-breeding season of $12.9 \pm 9.9 \mathrm{~km}$ per day
( $\mathrm{N}=265$ days with more than one location). Blue-and-yellow Macaws that migrated had an average daily movement index about half that of Scarlet Macaws during the non-breeding season (6.6 $\pm 4.0 \mathrm{~km}$ per day, $\mathrm{N}=59$ days with more than one location). This difference, while quite large, was not statistically significant (least squares regression ${ }_{\text {(with bird and number of locations as random effect) }} \mathrm{R}^{2}$ $=0.21, \mathrm{~F}_{1,2}=13.5, \mathrm{P}=0.1, \mathrm{~N}=4$ Scarlet individuals and $\mathrm{N}=3$ Blue-and-yellow individuals). The migratory individuals of both species did not differ significantly in their daily movements during the breeding season (least squares regression, $\mathrm{R}^{2}=0.30, \mathrm{~F}_{1,5}=$ $1.2, \mathrm{P}=0.58)$.

\section{Exploratory flights}

On eleven different days, three different Scarlet Macaws and three different Blue-and-yellow Macaws engaged in what appear to be "exploratory flights" defined as days with movements $>5 \mathrm{~km}$ from the initial location, with the final location $<2 \mathrm{~km}$ from the initial location. On the days with exploratory flights, the birds moved a total of $19 \pm 8.7 \mathrm{~km}(\mathrm{~N}=11$, range 9.5 to $36.5 \mathrm{~km})$. These flights were all during the non-breeding season. These flights could only be detected on days with at least three locations. Of the 317 total days with at least three locations in the nonbreeding season, we recorded these presumed exploratory flights on about $3.4 \%$ of these days. However, transmission covered only $\sim 5$ to 8 of the 12 hours of daylight each transmission day $(<65 \%$ of the potential activity time). As a result, additional exploration flights were likely missed and may have occurred on up to $5 \%$ of days during the non-breeding season. 
Table 3. Daily movement indices for Scarlet and Blue-and-yellow Macaws during the breeding and non-breeding seasons in southeastern Peru. Data are presented separately for birds that migrated during their deployments and those from 2009 that did not migrate during their deployments. Movement index (in $\mathrm{km}$ ) is the distance moved between subsequent locations on the same day. Since we averaged $<4$ locations per day per bird, the movement index is not equivalent to total daily movement. As movements by individuals varied greatly among deployments and we are analyzing for variations in movement within each year, data are analyzed at the level of deployment. Statistical results in the final four columns were generated using a least squares regression with daily movement index as the dependent variable, season as the dependent variable and deployment and number of locations as random effects. Data are presented as mean \pm standard deviation $(\mathrm{N})$.

\begin{tabular}{|c|c|c|c|c|c|c|c|c|c|c|}
\hline \multirow[b]{2}{*}{ Species } & \multirow[b]{2}{*}{ Deployments } & \multirow[b]{2}{*}{ Birds } & \multicolumn{2}{|c|}{ Breeding } & \multicolumn{2}{|c|}{ Non-breeding } & \multirow[b]{2}{*}{$\mathrm{R}^{2}$} & \multirow[b]{2}{*}{$\mathrm{F}$} & \multirow[b]{2}{*}{$\mathrm{df}(\mathrm{F})$} & \multirow[b]{2}{*}{$\mathrm{P}$} \\
\hline & & & $\begin{array}{c}\text { Daily } \\
\text { movement } \\
\text { index }\end{array}$ & $\begin{array}{c}\text { Locations } \\
\text { per day }\end{array}$ & $\begin{array}{c}\text { Daily } \\
\text { movement } \\
\text { index }\end{array}$ & $\begin{array}{c}\text { Locations } \\
\text { per day }\end{array}$ & & & & \\
\hline \multicolumn{11}{|l|}{ Scarlet Macaw } \\
\hline Migratory & 6 & 4 & $\begin{array}{c}8.9 \pm 6.6 \\
(246)\end{array}$ & $\begin{array}{c}4.1 \pm 1.8 \\
(259)\end{array}$ & $\begin{array}{c}12.9 \pm 10 \\
(265)\end{array}$ & $\begin{array}{c}4.4 \pm 1.6 \\
(272)\end{array}$ & 0.19 & 18.7 & 2,412 & $<0.0001$ \\
\hline Non-migratory & 2 & 2 & $\begin{array}{c}5.9 \pm 4.7 \\
(76)\end{array}$ & $\begin{array}{c}3.0 \pm 1.6 \\
(96)\end{array}$ & $\begin{array}{c}5.7 \pm 4.9 \\
(79)\end{array}$ & $\begin{array}{c}2.4 \pm 1.3 \\
\quad(104)\end{array}$ & 0.44 & 6.4 & 1,147 & 0.1 \\
\hline \multicolumn{11}{|c|}{ Blue-and-yellow Macaw } \\
\hline Migratory & 3 & 3 & $\begin{array}{c}6.0 \pm 4.3 \\
(43)\end{array}$ & $\begin{array}{c}2.3 \pm 1.7 \\
(80)\end{array}$ & $\begin{array}{c}6.6 \pm 4.0 \\
(59)\end{array}$ & $\begin{array}{c}3.3 \pm 2.2 \\
(93)\end{array}$ & 0.34 & 0.31 & 1,99 & 0.58 \\
\hline Non-migratory & 1 & 1 & $\begin{array}{c}12.4 \pm 9.1 \\
(66)\end{array}$ & $\begin{array}{c}3.2 \pm 1.5 \\
(76)\end{array}$ & $\begin{array}{c}9.6 \pm 8.3 \\
(26)\end{array}$ & $\begin{array}{c}3.4 \pm 1.6 \\
(28)\end{array}$ & 0.45 & 4.9 & 1,89 & 0.03 \\
\hline
\end{tabular}

\section{Seasonal movements}

The seasonal range shifts were initiated with a single large movement away from the breeding area (Scarlet, $28.0 \pm 11.0 \mathrm{~km}$, range 11.3 to $43.1 \mathrm{~km}, \mathrm{~N}=8$ deployments, Blue-and-yellow, 44 $\pm 18 \mathrm{~km}$, range 31 to $64 \mathrm{~km}, \mathrm{~N}=3$ birds, Tables 4 and A1.2). Only one Scarlet Macaw left the breeding range during the breeding season: on 1 March Franz in 2013 was recorded twice ( 8 hours apart) at a site about $20 \mathrm{~km}$ from the nest. Other than this one instance, all macaws of both species remained clearly within their normal breeding season ranges until they made their first large seasonal shifts.

Members of both species that migrated were first detected outside their breeding ranges on 2 April \pm 19 days $(\mathrm{N}=11$ departures total among 7 individuals). Mean departure dates for the two species were identical (2 April). The Scarlet Macaws occupied the non-breeding ranges for $140 \pm 22$ days (range 107 to 165 days, $\mathrm{N}$ $=8$ deployments on 4 individuals, Fig. 2 and Table A1.3). The Blue-and-yellow Macaws occupied the non-breeding ranges for $136 \pm 71.9$ days (range 53 to 179 days, $\mathrm{N}=3$ birds, Table A1.3) and these values did not differ significantly between the species when analyzed at the level of the individual or the deployment (Wilcoxon rank-sum: $\chi^{2}<0.67, \mathrm{DF}=1, \mathrm{P}>0.4$ ).

The Scarlet Macaws were first detected back in their breeding ranges on 21 August \pm 19 days $(\mathrm{N}=8$ deployments 4 individuals, Fig. 2, Table A1.4). The Blue-and-yellow Macaws were first detected in their breeding season ranges on average on the same date as the Scarlet Macaws (21 August \pm 27 days, Table A1.4). The return to the breeding range was more temporally variable compared to the departures (Fig. 2). After returning to their breeding season ranges, all remained in these ranges until their collars ceased functioning $98.9 \pm 48.1$ days later (range 28 to 165 days, $\mathrm{N}=7$ individuals, 11 deployments).
Fig. 2. Timing of the annual cycle of Scarlet Macaw movements in the Tambopata Region of southeastern Peru. For each stage in the annual cycle, the individual data points are plotted as short vertical lines and the curves above and below the points show the general distribution. Where there are overlapping points, the plotted lines are longer. The long dark lines show the means for each group. This figure shows that macaws leave their breeding areas shortly after the young fledge and return about 4.5 months later, almost three months before eggs are laid in the next season.

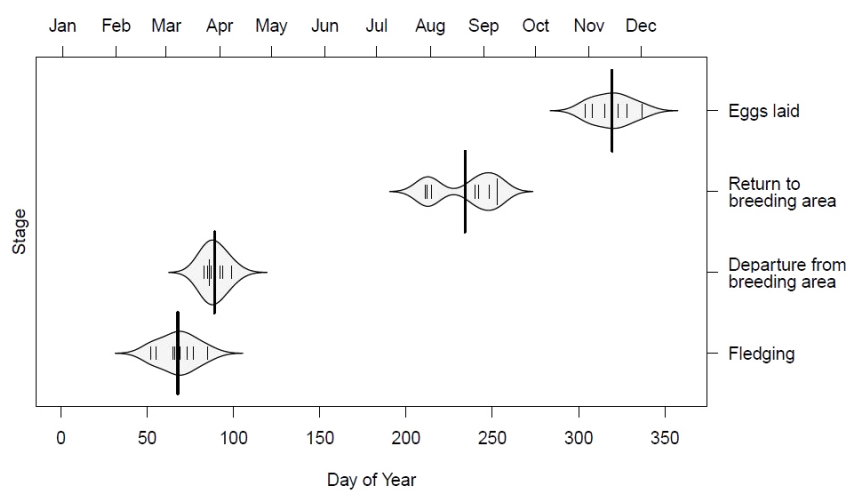

The chicks of the breeding Scarlet Macaws fledged 8 March \pm 11 days $(\mathrm{N}=8$ breeding attempts by 4 different individuals, Fig. 2, Table A1.2). The collared Scarlet Macaws departed their breeding ranges $25.3 \pm 10.7$ days after their chicks fledged (range 10 to 38 days, $\mathrm{N}=8$ deployments on 4 birds, Fig. 2, Table A1.2). All but one of the known breeding Scarlet Macaws (Ceiba, the only known female collared) returned to our field site to breed again in the year following deployment. On average the birds laid eggs 
Table 4. Spatial use parameters in the breeding and non-breeding seasons for Scarlet and Blue-and-yellow Macaws marked with Argos satellite transmitters in the lowlands of southeastern Peru from 2008 to 2016. Breeding season ended when the birds departed from their breeding areas (First departure from breeding) and began again when birds returned to their breeding range for the last time. The "Distance to first location outside breeding" is the distance from the nest (for Scarlet) or from the center of the breeding range (for Blue-and-yellow) to the first location outside the breeding range. The Argos collars used did not broadcast every day or receive locations on each broadcast day (see Table 1), so the "Days with locations" is the number of days where the system calculated usable locations of the birds. During the non-breeding season, we present the number of dates on which birds were detected in the breeding area (Dates detected back in breeding range). The "Distance from breeding range" was calculated as the distance of the bird from the nest (for Scarlets) or from the center of the breeding season range (for Blue-and-yellows where nesting status was not known). The values for the three non-migratory birds from 2009 are not included in this table, but their information is presented in Table A1.4. The " $\mathrm{N}$ " values represent the total number of deployments used in calculations. The final three columns show the results of a Wilcoxon rank-sum test (1-way $\chi^{2}$ approximation) comparing the values for Scarlet and Blue-and-yellow macaws. Details of each individual bird are given in Tables A1.2 and A1.4.

\begin{tabular}{|c|c|c|c|c|c|c|c|c|c|}
\hline & \multicolumn{3}{|c|}{ Scarlet Macaw } & \multicolumn{3}{|c|}{ Blue-and-yellow Macaw } & \multicolumn{3}{|c|}{ Wilcoxon rank-sum tests } \\
\hline & Mean & SD & $\mathrm{N}$ & Mean & $\mathrm{SD}$ & $\mathrm{N}$ & $\chi^{2}$ & DF & $\mathrm{P}$ \\
\hline \multicolumn{10}{|l|}{ Breeding season } \\
\hline Duration in days & 163 & 42 & 8 & 137 & 67 & 3 & 0.8 & 1 & 0.4 \\
\hline Days with locations & 32 & 9 & 8 & 27 & 14 & 3 & 0.3 & 1 & 0.6 \\
\hline Last location in breeding range (date) & 29-Mar & 5.4 & 8 & 27-Mar & 40 & 3 & 0.7 & 1 & 0.4 \\
\hline Distance to first location outside breeding $(\mathrm{km})$ & 28 & 11 & 8 & 44 & 18 & 3 & 1.5 & 1 & 0.2 \\
\hline Last return to breeding (date) & 21-Aug & 18 & 8 & 21-Aug & 26 & 3 & 0 & 1 & 1 \\
\hline Last return (days before egg laying) & 88 & 27 & $7^{+}$ & \multicolumn{3}{|c|}{ Unknown $^{\dagger}$} & \multicolumn{3}{|c|}{ Unknown $^{\dagger}$} \\
\hline \multicolumn{10}{|l|}{ Non-breeding season } \\
\hline First location & 2-Apr & 5.2 & 8 & 2-Apr & 42 & 3 & 0.67 & 1 & 0.4 \\
\hline First location non-breeding (days post fledge) & 25 & 11 & 8 & \multicolumn{3}{|c|}{ Unknown $^{\dagger}$} & \multicolumn{3}{|c|}{ Unknown $^{\dagger}$} \\
\hline Last location & 20-Aug & 18 & 8 & 16-Aug & 29 & 3 & 0.17 & 1 & 0.7 \\
\hline Duration (days) & 140 & 22 & 8 & 136 & 72 & 3 & 0.2 & 1 & 0.9 \\
\hline Days with locations & 34 & 6.7 & 8 & 31 & 20 & 3 & 1.3 & 1 & 0.26 \\
\hline Dates detected back in breeding range & 11 & 10 & 8 & 1.0 & 1.0 & 3 & 3.4 & 1 & 0.065 \\
\hline \multicolumn{10}{|l|}{ Distance from breeding range } \\
\hline Mean & 39 & 30 & 8 & 81 & 48 & 3 & $\S$ & 1,9 & 0.1 \\
\hline $\operatorname{Max}$ & 79 & 53 & 8 & 112 & 51 & 3 & 1.8 & 1 & 0.18 \\
\hline
\end{tabular}

The breeding status of Blue-and-yellow Macaws was unknown.

One Scarlet Macaw did not return to nest the year after tracking but returned to breed the year after.

${ }^{\S}$ The distance from the nesting range were tested with a least squares regression with the individual bird as a random effect. The resulting degrees of freedom and $\mathrm{P}$ values are provided.

$88 \pm 27$ days after returning to their breeding ranges (range 51 125 days, $\mathrm{N}=7$ deployments on 3 individual birds, Fig. 2, Table A1.4).

\section{Return visits to the breeding ranges}

During the non-breeding season, the Scarlet Macaws with known nest sites returned to the area near the nest (within $7 \mathrm{~km}$ ) on 9.8 \pm 6.3 days (range 3 to 18 days, $\mathrm{N}=4$ birds, Tables 4 and A1.2). During the non-breeding season, only two of the three migrant Blue-and-yellow Macaws returned to within $7 \mathrm{~km}$ of the center of the breeding range (Table A1.2) and overall they averaged only $1 \pm 1$ return during the non-breeding season (range 0 to $2, N=3$ birds, Tables 4 and A1.2). The difference in number of return visits between the species was significant (Wilcoxon rank-sum: $\chi^{2}=4.5$, $\mathrm{DF}=1, \mathrm{P}=0.03)$. One of the returns to the breeding area by Blue-and-yellow Macaws, was noteworthy due to the large distance traveled over the short time period: Charming was 146 $\mathrm{km}$ from the center of its breeding area on 18 August, then recorded on 22 August within $3 \mathrm{~km}$ of the center of its breeding home range, then recorded on 26 August in the same area where it had been on 18 August, $146 \mathrm{~km}$ from the breeding range.

\section{Direction of seasonal movements}

The non-breeding ranges for all three Blue-and-yellow Macaws were to the east-southeast of the breeding ranges (mean azimuth $_{\text {Blue-and-yellow }}=114.8^{\circ} \pm 5.0^{\circ}$, range $110^{\circ}$ to $120^{\circ}, \mathrm{N}=3$ birds, Figures 1, A2.12 to A2.14). This stood in stark contrast to the Scarlet Macaws that expanded their ranges to the northnortheast during the non-breeding season (mean azimuth Scarlet $=$ $22.7^{\circ} \pm 31.0^{\circ}, \mathrm{N}=4$ individuals, Wilcoxon rank-sum: $\chi^{2}=4.50$, $\mathrm{DF}=1, \mathrm{P}=0.03$, Figures $1, \mathrm{~A} 2.3$ to $\mathrm{A} 2.10$ ).

\section{Intra-individual variation among years}

We obtained usable data for more than one season for two individual birds: Franz in 2012 and 2013 and Angeles in 2011, 2012, 2013, and 2016. Franz in 2013 used a total range (MCP) and non-breeding core range three to five times larger than it did in 2012 (Tables 1 and 2). However, the 2013 breeding core area was $<40 \%$ of the size of what it was in 2012. Angeles' use of the landscape was also very variable among years. The spatial overlap in overall ranges among years (MCP) for Angeles was $55 \pm 31 \%$ ( $N=12$ overlap values) which is very similar to the $57 \pm 29 \%$ ( $N$ $=20$ ) of overlap seen among different individuals ( $\mathrm{t}$-test on arcsine transformed values, $\mathrm{t}=0.23, \mathrm{df}=17.7, \mathrm{P}=0.8$ ). Similarly, non- 
breeding core area overlap among years for Angeles $21 \pm 21 \%(\mathrm{~N}$ $=12)$ was similar to the $21 \pm 23 \%(\mathrm{~N}=20)$ from distinct birds $(\mathrm{t}-$ test on arcsine transformed values, $\mathrm{t}=0.48$, $\mathrm{df}=23.5, \mathrm{P}=0.6)$. Only the overlap of the breeding core areas ( $72 \pm 28 \%, \mathrm{~N}=12$ ), which are concentrated around the nest, were greater for Angeles among years than they were for distinct individuals $(52 \pm 29 \% \mathrm{~N}$ $=20, \mathrm{t}$-test on arcsine transformed values, $\mathrm{t}=1.76, \mathrm{df}=14.9, \mathrm{P}$ $=0.05)$.

\section{Use of protected areas}

All birds were captured approximately $25 \mathrm{~km}$ from the edge of the 1.36 million ha protected area complex that included the Tambopata National Reserve and Bahuaja Sonene National Park (SERNANP 2015). None of the macaws we collared of either species left these protected areas during the breeding season. Similarly, none of the macaws tracked in 2009 that did not migrate (two Scarlet and one Blue-and-yellow) left the protected areas at any time during their deployments.

However, all of the remaining Scarlet Macaws and all but one of the Blue-and-yellow Macaws that migrated, departed from the protected areas during the non-breeding seasons. All Scarlet Macaws that migrated had at least parts of their non-breeding season core areas outside the protected areas $(\mathrm{N}=4$ birds, 8 deployments). On average the migratory Scarlet Macaws spent 41 $\pm 31 \%$ of the non-breeding season outside the protected areas (range 9 to $96 \%, \mathrm{~N}=8$ deployments, Figures A2.3 to A2.10). The use of protected areas by Blue-and-yellow Macaws was slightly more complex, as one bird (Tiny) crossed out of Peru and spent part of the breeding season in Madidi National Park in Bolivia (total size 1.9 million ha) which abuts Bahuaja-Sonene National Park (Fig. A2.12). In total, two of three migratory Blue-andyellow Macaws had non-breeding season core areas outside of protected areas. On average, these migratory Blue-and-yellows spent $39 \pm 50 \%$ of the non-breeding season outside of the protected areas (range 0 to $96 \%, \mathrm{~N}=3$ birds, Figures A2.12 to A2.14).

\section{DISCUSSION}

As hypothesized, both macaw species had very large home ranges: the maximum movements by individuals from the point of capture ranged from 15 to $164 \mathrm{~km}$ and individuals covered areas of $\sim 227$ to $\sim 5600 \mathrm{~km}^{2}$. Our results show that Scarlet Macaw and Blueand-yellow Macaw movement patterns were overall very similar. Home range sizes did not differ between these two similarly sized congeners. Maximum daily movements and daily movements during the breeding season were also similar. For migratory individuals, both species showed abrupt transitions from the breeding range to the non-breeding range with single movements of over $10 \mathrm{~km}$ and both departed from the breeding range and returned to the breeding range on the same day on average. These similarities in breeding home range size and movements may be because both species have relatively high dietary overlap during the breeding season (Adamek 2011, Lee et al. 2014) and both may respond in similar ways to the seasonal drop in food supplies at the end of breeding (Brightsmith et al. 2018, Carrara et al. 2019).

Of all the parameters tested in this work, only two differed significantly between the species: 1) Scarlet non-breeding ranges lay mostly to the north-northeast of the breeding ranges and those of Blue-and-yellows lay to the east-southeast and 2) Scarlet Macaws returned to the breeding range more times during the non-breeding season. As a result of the similarity between these species, they are considered together throughout the majority of the ensuing discussion.

\section{Home Ranges}

As hypothesized, individuals of both species of macaws moved over areas of thousands of ha. In the only previous study of adult Scarlet and Blue-and-yellow Macaws home ranges, Adamek's (2011) non-breeding MCP ranges averaged 20 times larger for Scarlet Macaws and over 45 times larger for Blue-and-yellow compared to breeding ranges. As in our study, Adamek found no difference in range sizes between the two species. However, our satellite-derived ranges were about 6 times larger (breeding) and 1.6 to 4 times larger (non-breeding) than Adamek's VHF-derived ranges. It is difficult to know how much of the difference was due to tracking methodology versus real biological differences, but Adamek (2011) states that birds were not always located, and some crossed international boundaries, preventing her team from documenting the full range of movements.

\section{Other parrot home ranges}

There have been relatively few telemetry-based home range studies of wild parrots, and those that exist have used a diversity of time periods and methods. This being said, the MCP home ranges we found in our study $\left(227\right.$ to $\left.5,647 \mathrm{~km}^{2}\right)$ are one or more orders of magnitude larger than most parrot MCP ranges reported to date (Lindsey et al. 1991, Robinet et al. 2003, SalinasMelgoza 2003, Stahala 2008, Meyer 2010, Adamek 2011, SalinasMelgoza et al. 2013). However our large range sizes are not unprecedented: Northern Mealy Parrots (Amazona guatemalae) from Tikal, Guatemala covered about $10,000 \mathrm{~km}^{2}$ including areas $>200 \mathrm{~km}$ from their nests (Bjork 2004). In addition, other tropical frugivores annually move hundreds of kilometers across multiple life zones (Holbrook et al. 2002, Powell and Bjork 2004).

\section{Daily movements}

The small number of locations generated per day prevented us from effectively quantifying the macaws' daily movements. However, we confirmed that these macaws were able to move at least 20 to $40 \mathrm{~km}$ per day. We also recorded one individual flying back and forth from its nest during the non-breeding season, covering nearly $300 \mathrm{~km}$ in 8 days or less. Given that large macaws can fly at speeds of $40 \mathrm{~km}$ per hour (DJB unpublished data) the actual daily movement values for both species of macaws are likely very much higher than what we report here.

\section{Exploratory flights}

Long distance movements on single days are difficult to detect with traditional VHF telemetry. However, Argos and GIS telemetry have provided new insights into daily movements of many types of birds (García-Ripollés et al. 2011, Wheat et al. 2017, McDuie et al. 2019, Rakowski et al. 2019). We found that our macaw species made long, looping, exploratory flights of 10 to $40 \mathrm{~km}$ that ended near the starting point on $3 \%$ to $5 \%$ of the days during the non-breeding season. These exploratory flights differ from major migration movements because in exploratory flights the birds fly long distances but return to areas near where they started. Exploratory flights have been recorded using GPS 
tracking of released black-cockatoos in Australia but these were by released individuals searching for conspecifics so it is uncertain how common they are in natural populations (Rycken et al. 2019). The exploratory flights we observed occurred only during the nonbreeding season when food supplies were low and the birds use relatively small patches far from their breeding ranges. This suggest that these long-lived and highly intelligent psittacines may be using these flights to survey their surroundings and gather information on spatial and temporal distribution of food and habitats.

\section{Seasonal movements}

Both species occupied relatively small home ranges during the breeding season. During the non-breeding season, birds that migrated expanded their home ranges and included areas as far as $160 \mathrm{~km}$ from their nests. This movement away from the nesting area was not a surprise due to the sharp drop in food supplies throughout our study region during the non-breeding season (Adamek 2011, Lee et al. 2014, Brightsmith et al. 2018). This finding also supports the previously published hypothesis that seasonal variation in abundance and clay lick use in the Tambopata region are driven in large part by birds moving in and out of the area (Brightsmith 2004, Brightsmith et al. 2018).

During the non-breeding season our data suggest that most birds moved systematically from one small part of their non-breeding range to another small part of their non-breeding range. For areas distant from the nests, the macaws commonly visited them only once per season for a few weeks before moving on to another relatively small section of the non-breeding range. Because parrot movements in the non-breeding season are known to be driven by local food availability (Ragusa-Netto 2004, Salinas-Melgoza and Renton 2005, Ragusa-Netto 2006), the most likely hypothesis is that these birds were exploiting specific food patches for a few weeks before moving on to new food patches.

In our study, nearly all Scarlet and Blue-and-yellow Macaws that migrated away from their breeding season ranges made at least one return to the breeding range or nest area before returning to the more distant parts of their non-breeding ranges. This includes a Blue-and-yellow Macaw that traveled nearly $300 \mathrm{~km}$ round trip to make a brief visit to breeding range during the late nonbreeding season. Our findings are similar to those from Greatgreen Macaws that frequently returned to the nesting areas for brief visits from sites up to $40 \mathrm{~km}$ away (Powell et al. 1999). Competition for nest sites in our study region is intense for both species and is thought to be even higher for Scarlet Macaws that compete both with conspecifics and the larger Red-and-green Macaws (Ara chloropterus) (Renton 2004, Renton and Brightsmith 2009). These returns may be used by individuals to monitor the status of the food supplies in the area surrounding the nest, or check on the status of the nest site itself, as nest sites can become unusable due to tree falls or other events (Vaughan et al. 2003).

\section{Migration patterns}

As hypothesized, some macaws remained at the study site yearround $(\sim 30 \%)$ while others migrated away from the breeding season ranges $(\sim 70 \%)$. However, all the birds that did not migrate were captured in 2009, suggesting that either there was something different about 2009 or that our sampling was biased towards resident birds in that year. From 2006 until 2020 we conducted macaw and parrot point counts at our study site (DJB unpublished data). In 2008 and 2010, the years in which tagged Blue-andyellow Macaws at our study site migrated, abundance for that species fell by $34 \%$ and $59 \%$ respectively after the breeding season. By contrast, in 2009 the abundance of Blue-and-yellow Macaws increased by $175 \%$ post breeding, suggesting that the lack of migration by the lone Blue-and-yellow during 2009 may have been related to unusual local conditions. Given that this was an ENSO event (NOAA PSL 2020), it could have changed plant phenology and corresponding food supplies at the landscape level.

Across its range, Blue-and-yellow Macaws seems to have a diversity of migration patterns. The species' abundance showed little or no seasonal fluctuations during studies in eastern Ecuador, eastern Brazil, and the Manu region of Peru suggesting these populations were mostly resident (Renton 2002, Karubian et al. 2005, Silva 2013). However, seasonal migration of the species has been documented by studies in southeastern Peru and the Pantanal (Adamek 2011, Carrara et al. 2019, this study).

For Scarlet Macaws, there is no indication that the failure of the tagged individuals to migrate in 2009 was due to a community wide pattern: after breeding the abundance of the species dropped by $76 \%$ in 2009 and by $60 \pm 11 \%$ in the years when tagged individuals migrated ( $\mathrm{N}=4$ years, 2011, 2012, 2013, and 2016). Unfortunately, our capture and tagging regimes differed among the years of our study, complicating the interpretation of our movement results. The two birds that did not migrate during 2009 were both captured at the clay lick and we have no evidence that they nested. One of these, Danny, was banded as a chick in early 2005 , so was about four years old when captured and was likely not breeding due to his young age. The other resident, Wheezy, showed a deeply wrinkled face typical of the 20-year-old released birds at TRC (Brightsmith et al. 2005), was almost certainly not a young bird, and may not have been breeding due to old age. All of the other Scarlet Macaws in this study were trapped at nests and known to have fledged young the years they were tracked. These data suggest that breeding status may be linked to migration at our site, but annual variation in migration tendencies cannot be ruled out. Interpretation is further complicated by the fact that, macaw pairs with young were commonly detected at our site every year of the study from March through August (DJB unpublished data) suggesting that not all successful breeders migrate away from the area. For Great-green Macaws in Costa Rica migration may be linked to breeding status, as all migratory birds had young but among the birds that did not migrate, some had young and some did not (Powell et al. 1999). However in Belize, surveys of Scarlet Macaws at multiple sites suggest that it is non-breeders that migrate, leaving the breeding grounds at the onset of nesting (McReynolds 2012).

Previous studies suggest that Scarlet Macaw migration patterns differ widely across the range. Observational studies suggest that some areas have only fully resident birds (Iñigo-Elias 1996, Vaughan pers. comm.) and some areas have partially migratory populations where 1) migrants depart after breeding ends (Renton 2002), 2) non-breeders depart at the onset of breeding (McReynolds 2012), and 3) local breeding populations are augmented by migrants from other areas (Lee and Marsden 2012, R. Leon pers. comm.). In some areas Scarlet Macaw populations 
may be fully migratory: observations suggest that non-breeding individuals visit sites in Belize during the breeding season then all depart when the locally abundant food is depleted (McReynolds 2012) and in the Peten of Guatemala, satellite tracking of individuals and local surveys show that all the Scarlet Macaws leave the area after breeding (R. Garcia unpublished manuscript and personal communication). Taken as a whole, this evidence suggests that populations of both Scarlet and Blue-and-yellow Macaws undertake a complex mix of different migration patterns across their ranges and a great deal more work will be needed to clarify when and why these birds migrate.

\section{Timing of seasonal movements}

Macaws in our study that migrated undertook non-breeding seasonal migrations that lasted about four to five months (Fig. 2). This is similar to information from observations and tracking studies which suggest annual post breeding migrations of large macaws last from about 3 to 6 months: 3 months for Scarlet in Guatemala (R. Garcia-Anleu personal communication), 4 to 5 months for Military in Mexico (Reyes Macedo 2007), 5 months for Blue-and-yellow in Brazil (Carrara et al. 2019), and 3 to 6 months for Great Green in Costa Rica (Powell et al. 1999).

Given the vulnerability and poor flying ability of macaws' dependent young (Myers and Vaughan 2004), we were surprised that our marked Scarlet Macaws left their breeding ranges and flew an average of $\sim 30 \mathrm{~km}$ only 15 to 38 days after their young fledged. However, this type of movement is not unprecedented: studies report movements of 10's of kms within two to three weeks of fledging for Scarlet Macaws, Long-billed Corellas (Cacatua tenuirostris), and a variety of Amazona parrots (Smith and Moore 1992, Enkerlin-Hoeflich 1995, Salinas-Melgoza 2003, Myers and Vaughan 2004, Faegre and Berkunsky 2014).

\section{Directions of seasonal movements}

In our work, perhaps the most visible difference between the two macaw species was the major axis of movement: long distance movements by Scarlet Macaws were to the northeast (which paralleled the Tambopata River) and movements by Blue-andyellow Macaws were to the east-southeast (parallel to the foothills of the Andes, Fig. 1). Surprisingly, Adamek (2011) also found that Blue-and-yellow Macaws moved to the east-southeast parallel to the base of the Andes and Scarlet Macaws moved predominantly to the northeast. During the non-breeding season, the dietary overlap between these two species apparently drops and they exploit different preferred food sources (Adamek 2011). As a result, these differing axes may correspond with spatial differences in habitat and food resources. Previous studies suggest that Blue-and-yellow Macaws prefer floodplain and palm swamp habitats in our study region (Adamek 2011), but it is uncertain if this habitat is more common along the base of the Andes. Our Scarlet Macaws followed the general direction of the floodplain of the Tambopata River, and floodplains are known to be important macaw habitats (Renton 2002, Adamek 2011). However, at Adamek's site the Scarlet Macaws did not follow a single floodplain like our birds, instead they crossed drainages perpendicularly, which calls in to doubt the simple hypothesis suggested by our work that the Scarlet Macaws simply travel along rivers and floodplains.

This sort of non-random orientation in annual post-breeding migration was also found in migrating Blue-and-yellow Macaws in the Pantanal, and Scarlet Macaws and Northern Mealy Parrots in Guatemala (Bjork 2004, Carrara et al. 2019, R. Garcia-Anleu personal communication). These studies suggest that these large parrots have detailed knowledge of the landscape that allows them to orient towards specific distant landscape features.

\section{Intra-individual variation among years}

Reports of annual variation in movement patterns by individual parrots are rare. However, one of our two birds tracked in multiple years migrated both years. The other showed clearly migratory patterns in three of four years and then remained nearer the nest for the majority of the fourth non-breeding season. The fact that this second bird (Angeles) had both the largest and smallest nonbreeding season ranges for Scarlet Macaw registered in this study shows the magnitude of interannual variation in this system. There is little information in the literature on individual variation among years in parrot movement patterns. However, of three young Lilac-crowned Parrots tracked for two seasons in western Mexico, one migrated both years, one did not migrate either year, and one migrated one year but not the next (Salinas-Melgoza 2003). Annual fluctuations in parrot food supplies have been well documented (Masello and Quillfeldt 2004, Renton and SalinasMelgoza 2004) so it is not surprising that migration decisions and destinations could vary widely among years, even for the same individuals. However, there is need for more information on interannual variation in movement patterns at both the individual and population levels.

\section{Ranging patterns and protected areas}

Throughout the globe, highly mobile animals are known for moving from protected areas into zones with increased threats (Plumb et al. 2009, Tubelis 2010, Lowry and Pérez-Elissetche 2016, Povilitis 2016). In our study, the three birds tracked in 2009 remained inside the 1.36 million ha protected area complex, as did all our other birds during the breeding season. These data suggest that the protected areas provide the resources these birds need during breeding. However, annual home ranges averaged nearly 200,000 ha for both species and all individuals combined ranged over an area of $>2,100,000$ ha. In addition, all but one of the birds that migrated spent significant amounts of time outside the reserves. This work and that of others suggest that managers need to maintain resources for macaws not only in protected areas but in surrounding landscapes at the level of tens-of-thousands to millions of hectares when trying to meet the year-round requirements of highly mobile parrot populations (Powell et al. 1999, Salinas-Melgoza 2003, Bjork 2004, Adamek 2011, Allen and Singh 2016, Lowry and Pérez-Elissetche 2016).

Conserving macaws and their habitats outside protected areas is vital. If suitable macaw habitat remained only within the 1.36 million ha protected areas we studied, it could result in the loss of the up to $70 \%$ of the individuals that migrated and a disproportionate number of successful breeders. If these individuals are lost during migrations, the population would lose not only the individuals, their reproductive capacity, and their genetic diversity, but also their accumulated knowledge of the spatial and temporal distribution of foods and habitats in the surrounding landscape. This knowledge is accumulated throughout their lives and much of this knowledge may be passed to subsequent generations during the post fledging seasonal migrations documented here. The loss of this knowledge of 
Avian Conservation and Ecology 16(1): 14

distant areas may reduce the availability of resources for current generations, reduce the ability of populations to survive climate driven food fluctuations, and even hinder the long-term recovery of populations unable to exploit rich, seasonally available food supplies in distant locations. Future parrot studies of nonmigratory populations that have suffered extreme bottlenecks (Beissinger et al. 2008, Vaughan 2019) should consider the possibility that loss of traditional migratory behaviors could be influencing current resource exploitation patterns and slowing population recovery.

\section{CONCLUSIONS}

Knowledge of parrot movements remains very limited and much of the best data remain in unpublished reports and theses (Powell et al. 1999, Salinas-Melgoza 2003, Bjork 2004, Adamek 2011, Lowry and Pérez-Elissetche 2016). As a result, psittacine movements and their consequences have not received the broad, order-wide syntheses and analysis published for other variables such as diet, nesting, clay lick use, and seed dispersal (Renton et al. 2015, Tella et al. 2015, Downs et al. 2019). However, our data, plus those from previous studies, suggest that many parrots show a complex mix of migratory and sedentary movement patterns that may vary among species and populations. Data are limited, but migration decisions may vary from year to year, even for the same individual. Temporal and spatial variations in food supplies likely drive these seasonal movements, but more research is needed to elucidate the drivers of these seasonal movements, identify key characteristics of sites visited during times of low food availability, and determine how managers can maintain key resources in multiuse landscapes outside protected areas.

While macaws may breed successfully in relatively small areas $\left( \pm 100 \mathrm{~km}^{2}\right)$, the large scale and highly variable post breeding movements of New World parrots documented to date confirm that parrot conservation needs to work at the scale of thousands to millions of hectares. Extreme population declines, resulting in the loss of migratory individuals may reduce survival and hamper long term population recovery in unexpected ways. Moving forward, new tracking technologies deployable on a wider array of parrot species are needed to allow researchers to fully explore the causes and consequences of these landscape level movement patterns and provide sound recommendations for global parrot conservation.

Responses to this article can be read online at: https://www.ace-eco.org/issues/responses.php/1822

\section{Acknowledgments:}

Thanks to Gabriela Vigo Trauco, the leaders and volunteers of the Macaw Society (formerly the Tambopata Macaw Project), Kurt Holle, and the staff of Tambopata Research Center. Thanks also to Stan Tomkiewicz Jr. of Telonics. Funding was provided by the Wildlife Protection Foundation, Parrot Fund USA, Phoenix Landing, Raleigh-Durham Caged Bird Society, Rainforest Expeditions, Schubot Avian Health Center, and private donors. EAH was supported by a postdoctoral fellowship from the ASUSFI Center for Biosocial Complex Systems and the Santa Fe
Institute. Permits for this research were granted by SERNANP, Peru and the Texas A\&M University Institutional Animal Care and Use Committee to DJB. All procedures contributing to this work comply with the ethical standards of the Texas A\&M University institutional guides on the care and use of laboratory animals.

\section{LITERATURE CITED}

Adamek, K. A. 2011. Temporal variation in space and resource use of macaws in the southeastern Peruvian Amazon. PhD dissertation, Texas A\&M University.

Allen, A. M., and N. J. Singh. 2016. Linking movement ecology with wildlife management and conservation. Frontiers in Ecology and Evolution 3:155. https://doi.org/10.3389/fevo.2015.00155

Beissinger, S. R., J. M. Wunderle Jr., J. M. Meyers, B.-E. Sæther, and S. Engen. 2008. Anatomoy of a bottleneck: diagnosing factors limiting population growth in the Puerto Rican Parrot. Ecological Monographs 78:185-203. https://doi.org//10.1890/07-0018.1

Bennett, P. M., and I. P. Owens. 1997. Variation in extinction risk among birds: chance or evolutionary predisposition? Proceedings of the Royal Society of London B: Biological Sciences 264:401-408. https://doi.org//10.1098/rspb.1997.0057

Berg, K. S., J. Socola, and R. R. Angel. 2007. Great Green Macaws and the annual cycle of their food plants in Ecuador. Journal of Field Ornithology 78:1-10. https://doi.org/10.1111/j.1557-9263.2006.00080. $\mathrm{x}$

Beyer, H. L. 2012. Geospatial Modeling Environment [Online]. Available: http://www.spatialecology.com/gme [Accessed 9 July 2019].

Bjork, R. 2004. Delineating patterns and process in tropical lowlands: Mealy Parrot migration dynamics as a guide for regional conservation planning. Ph.D. Dissertation, Oregon State University.

Bjork, R., and G. V. N. Powell 1995. Buffon's Macaw: some observations on the Costa Rican population, its lowland forest habitat and conservation. In: Abramson, J., Spear, B. L. \& Thomsen, J. B. (eds.) The large macaws: their care, breeding and conservation. Raintree Publications, Ft. Bragg, California, USA.

Bovo, A. A. A., K. M. P. M. B. Ferraz, M. Magioli, E. R. Alexandrino, É. Hasui, M. C. Ribeiro, and J. A. Tobias. 2018. Habitat fragmentation narrows the distribution of avian functional traits associated with seed dispersal in tropical forest. Perspectives in Ecology and Conservation 16:90-96. https://doi. org/10.1016/j.pecon.2018.03.004

Boyd, J. D., and D. J. Brightsmith. 2013. Error properties of Argos satellite telemetry locations using least squares and Kalman filtering. PLoS ONE 8: e63051. https://doi.org/10.1371/journal. pone. 0063051

Bridge, E. S., K. Thorup, M. S. Bowlin, P. B. Chilson, R. H. Diehl, R. W. Fléron, P. Hartl, R. Kays, J. F. Kelly, W. D. Robinson, and M. Wikelski. 2011. Technology on the move: recent and rorthcoming innovations for tracking migratory birds. BioScience 61:689-698. https://doi.org/10.1525/bio.2011.61.9.7 
Brightsmith, D. J. 2004. Effects of weather on parrot geophagy in Tambopata, Peru. Wilson Bulletin 116:134-145. https://doi. org/10.1676/03-087B

Brightsmith, D. J. 2005. Parrot nesting in southeastern Peru: seasonal patterns and keystone trees. Wilson Bulletin 117:296-305. https://doi.org/10.1676/03-087A.1

Brightsmith, D. J., J. Hilburn, A. Del Campo, J. Boyd, M. Frisius, R. Frisius, D. Janik, and F. Guillén. 2005. The use of hand-raised Psittacines for reintroduction: a case study of Scarlet Macaws (Ara macao) in Peru and Costa Rica. Biological Conservation 121:465-472. https://doi.org/10.1016/j.biocon.2004.05.016

Brightsmith, D. J., E. A. Hobson, and G. Martinez. 2018. Food availability and breeding season as predictors of geophagy in Amazonian parrots. Ibis 160:112-129. https://doi.org/10.1111/ ibi. 12515

Brightsmith, D. J., and E. Villalobos. 2011. Parrot behavior at a Peruvian clay lick. Wilson Journal of Ornithology 123:595-602. https://doi.org/10.1676/09-109.1

Carrara, L. A., P. D. T. Z. Antas, R. D. S. Yabe, F. K. Ubaid, S. B. D. O. Júnior, and L. P. Ferreira. 2019. Seasonal movements of Blue-and-yellow Macaw (Ara ararauna) in the northern Pantanal floodplains, Brazil. Wilson Journal of Ornithology 131:725-734. https://doi.org/10.1676/1559-4491-131.4.725

Collar, N. J. 1997. Family Psittacidae. In: Hoyo, J. d., Elliott, A. \& Sargatal, J. (eds.) Handbook of the Birds of the World. Lynx Edicions, Barcelona, Spain.

Downs, C. T., I. P. Bredin, and P. D. Wragg. 2019. More than eating dirt: a review of avian geophagy. African Zoology 54:1-19. https://doi.org/10.1080/15627020.2019.1570335

Dunning, J. B. 2008. CRC handbook of avian body masses. CRC Press, Boca Raton, Florida, USA. https://doi.org/10.1201/9781420064452

Enkerlin-Hoeflich, E. C. 1995. Comparitive ecology and reproductive biology of three species of Amazona parrots in northeastern Mexico. PhD Dissertation, Texas A\&M University.

Faegre, S., and I. Berkunsky. 2014. Post-fledging survival of Bluefronted Parrots. Ornitologia Neotropical 25:55-61.

Forshaw, J. M. 1989. Parrots of the World. Landsdowne Editions, Melbourne, Australia. https://doi.org/10.1515/9781400836208

Foster, R. B., T. Parker, A, A. H. Gentry, L. H. Emmons, A. Chicchón, T. Schulenberg, L. Rodríguez, G. Larnas, H. Ortega, J. Icochea, W. Wust, M. Romo, C. J. Alban, O. Phillips, C. Reynel, A. Kratter, P. K. Donahue, and L. J. Barkley 1994. The Tambopata-Candamo Reserved Zone of southeastern Peru: a biological assessment. Conservation International, Washington, DC, USA.

García-Ripollés, C., P. López-López, and V. Urios. 2011. Ranging behaviour of non-breeding Eurasian Griffon Vultures Gyps fulvus: a GPS-telemetry study. Acta Ornithologica 46:127-134. https://doi.org//10.3161/000164511x625892

Gilardi, J. D., and C. A. Toft. 2012. Parrots eat nutritious foods despite toxins. PloS One 7:e38293. https://doi.org/10.1371/ journal.pone. 0038293
Haig, S. M., D. W. Mehlman, and L. W. Oring. 1998. Avian movements and wetland connectivity in landscape conservation. Conservation Biology 12:749-758. https://doi.org//10.1111/ j.1523-1739.1998.97102.x

Holbrook, K. M., T. B. Smith, and B. D. Hardesty. 2002. Implications of long-distance movements of frugivorous rain forest hornbills. Ecography 25:745-749. https://doi.org/10.1034/ j.1600-0587.2002.250610.x

Holland, R. A., M. Wikelski, F. Kümmeth, and C. Bosque. 2009. The secret life of oilbirds: new insights into the movement ecology of a unique avian frugivore. PloS one 4:e8264-e8264. https://doi. org/10.1371/journal.pone.0008264

Iñigo-Elias, E. E. 1996. Ecology and breeding biology of the Scarlet Macaw (Ara macao) in the Usumacinta drainage basin of Mexico and Guatemala. Ph.D. dissertation, University of Florida.

Karubian, J., J. Fabara, D. Yunes, J. P. Jorgenson, D. Romo, and T. B. Smith. 2005. Temporal and spatial patterns of macaw abundance in the Ecuadorian Amazon. Condor 107:617-626. https://doi.org/10.1093/condor/107.3.617

Kennedy, C. M., and P. P. Marra. 2010. Matrix mediates avian movements in tropical forested landscapes: Inference from experimental translocations. Biological Conservation 143:2136-2145. https://doi.org/10.1016/j.biocon.2010.05.025

Kie, J. G., J. Matthiopoulos, J. Fieberg, R. A. Powell, G. Cagnacci, M. S. Mitchell, J. M. Gaillard, and P. R. Moorcroft. 2010. The home-range concept: are traditional estimators still relevant with modern telemetry technology? Philosophical Transactions of the Royal Society of London B: Biological Sciences 365:2221-2231. https://doi.org//10.1098/rstb.2010.0093

Lee, A. T. K., D. J. Brightsmith, M. P. N. Vargas, K. Q. Leon, A. J. R. Mejia, L. Y. Q. Huanca, A. K. Lee, and S. J. Marsden. 2014. Diet and geophagy across a western Amazonian parrot assemblage. Biotropica 46:322-330. https://doi.org/10.1111/ btp. 12099

Lee, A. T. K., and S. J. Marsden. 2012. The influence of habitat, season, and detectability on abundance estimates across an Amazonian parrot assemblage. Biotropica 44:537-544. https:// doi.org/10.1111/j.1744-7429.2011.00847.x

Lindsey, G. D., W. J. Arendt, J. Kalina, and G. W. Pendelton. 1991. Home range and movements of juvenile Puerto Rican Parrots. Journal of Wildlife Management 55:318-322. https://doi. org/10.2307/3809157

Lowry, J., and K. Pérez-Elissetche 2016. Resultatos finales de la liberación de la guacamaya verde (Ara militaris) "Petra Herrera". United Corridors AC. Querétaro, Mexico: United Corridors AC.

Masello, J. F., and P. Quillfeldt. 2004. Consequences of La Niña for the survival and growth of nestling Burrowing Parrots on the Atlantic coast of South America. Emu - Austral Ornithology 104:337-346. https://doi.org//10.1098/rstb.2010.0093

McDuie, F., M. L. Casazza, C. T. Overton, M. P. Herzog, C. A. Hartman, S. H. Peterson, C. L. Feldheim, and J. T. Ackerman. 2019. GPS tracking data reveals daily spatio-temporal movement patterns of waterfowl. Movement Ecology 7:6. https://doi. org/10.1186/s40462-019-0146-8 
McReynolds, M. S. 2012. Patterns of seasonal variation in diet, abundance, and movement of the Scarlet Macaw (Ara macao) in southern Belize. PhD Dissertation, Antioch University of New England.

Meyer, C. 2010. Spatial ecology and conservation of the endemic and endangered Red-fronted Macaw (Ara rubrogenys) in the Bolivian Andes. Diploma Thesis, Georg-August University Göttingen, Germany.

Meyers, J. M. 1994. Improved capture techniques for psittacines. Wildlife Society Bulletin 22:511-516.

Møller, A. P., D. Rubolini, and E. Lehikoinen. 2008. Populations of migratory bird species that did not show a phenological response to climate change are declining. Proceedings of the National Academy of Science. USA 105:16195-16200. https://doi. org//10.1073/pnas.0803825105

Morellato, L. P. C., B. Alberton, S. T. Alvarado, B. Borges, E. Buisson, M. G. G. Camargo, L. F. Cancian, D. W. Carstensen, D. F. E. Escobar, P. T. P. Leite, I. Mendoza, N. M. W. B. Rocha, N. C. Soares, T. S. F. Silva, V. G. Staggemeier, A. S. Streher, B. C. Vargas, and C. A. Peres. 2016. Linking plant phenology to conservation biology. Biological Conservation 195:60-72. https:// doi.org/10.1016/j.biocon.2015.12.033

Myers, M. C., and C. Vaughan. 2004. Movement and behavior of Scarlet Macaws (Ara macao) during the post-fledging dependence period: implications for in situ versus ex situ management. Biological Conservation Restoration and Sustainability 118:411-420. https://doi.org/10.1016/j.biocon.2003.09.018

Nathan, R. 2008. An emerging movement ecology paradigm. Proceedings of the National Academy of Science. USA 105:19050-19051. https://doi.org/10.1073/pnas.0808918105

NOAA PSL. 2020. Multivariate ENSO Index Version 2 (MEI.v2) [Online]. NOAA Physical Sciences Laboratory. Available: https:// psl.noaa.gov/enso/mei/ [Accessed 21 Dec 2020 2020].

Nycander, E., D. H. Blanco, K. M. Holle, A. d. Campo, C. A. Munn, J. I. Moscoso, and D. G. Ricalde. 1995. Manu and Tambopata: nesting success and techniques for increasing reproduction in wild macaws in southeastern Peru. In: Abramson, J., Spear, B. L. \& Thomsen, J. B. (eds.) The large macaws: their care, breeding and conservation. Raintree Publications, Fort Bragg, California, USA.

Olah, G., S. H. M. Butchart, A. Symes, I. M. Guzmán, R. Cunningham, D. J. Brightsmith, and R. Heinsohn. 2016. Ecological and socio-economic factors affecting extinction risk in parrots. Biodiversity and Conservation 25:205-223. https://doi. org/10.1007/s10531-015-1036-Z

Olah, G., G. Vigo, R. Heinsohn, and D. J. Brightsmith. 2014. Nest site selection and efficacy of artificial nests for breeding success of Scarlet Macaws (Ara macao) in lowland Peru. Journal for Nature Conservation 22:176-185. https://doi.org/10.1016/j. jnc.2013.11.003

Ortiz-Maciel, S. G., C. Hori-Ochoa, and E. Enkerlin-Hoeflich. 2010. Maroon-Fronted Parrot (Rhynchopsitta terrisi) breeding home range and habitat selection in the northern Sierra Madre Oriental, Mexico. Wilson Journal of Ornithology 122:513-517. https://doi.org/10.1676/08-002.1
Plumb, G. E., P. J. White, M. B. Coughenour, and R. L. Wallen. 2009. Carrying capacity, migration, and dispersal in Yellowstone bison. Biological Conservation 142:2377-2387. https://doi. org/10.1016/j.biocon.2009.05.019

Povilitis, T. 2016. Compassionate conservation for Yellowstone's wolves. Natural Areas Journal 36:334-339. https://doi. org/10.3375/043.036.0314

Powell, G., P. Wright, U. Aleman, C. Guindon, S. Palminteri, and R. Bjork 1999. Research findings and conservation recommendations for the Great Green Macaw (Ara ambigua) in Costa Rica. Centro Cientifico Tropical. San Jose, Costa Rica.

Powell, G. V. N., and R. Bjork. 2004. Habitat linkages and the conservation of tropical biodiversity as indicated by seasonal migrations of Three-Wattled Bellbirds. Conservation Biology 18:500-509. https://doi.org/10.1111/j.1523-1739.2004.00044.x

Ragusa-Netto, J. 2004. Flowers, fruits, and the abundance of the Yellow-chevroned Parakeet (Brotogeris chiriri) at a gallery forest in the south pantanal (Brazil). Brazilian Journal of Biology 64:867-877. https://doi.org/10.1590/S1519-69842004000500017

Ragusa-Netto, J. 2006. Dry fruits and the abundance of the Blueand-Yellow Macaw (Ara ararauna) at a cerrado remnant in central Brazil. Ornitologia Neotropical 17:491-500.

Rakowski, A. E., R. D. Elmore, C. A. Davis, S. D. Fuhlendorf, and J. M. Carroll. 2019. Thermal refuge affects space use and movement of a large-bodied galliform. Journal of Thermal Biology 80:37-44. https://doi.org/10.1016/j.jtherbio.2018.12.024

Renton, K. 2002. Seasonal variation in occurrence of macaws along a rainforest river. Journal of Field Ornithology 73:15-19. https://doi.org/10.1648/0273-8570-73.1.15

Renton, K. 2004. Agonistic interactions of nesting and nonbreeding macaws. Condor 106:354-362. https://doi.org/10.1093/ condor/106.2.354

Renton, K., and D. J. Brightsmith. 2009. Cavity use and reproductive success of nesting macaws in lowland forest of southeast Peru. Journal of Field Ornithology 80:1-8. https://doi. org/10.1111/j.1557-9263.2009.00198.x

Renton, K., and A. Salinas-Melgoza. 2004. Climatic variability, nest predation and reproductive output of Lilac-crowned Parrots (Amazona finschi) in tropical dry forest of western Mexico. Auk 121:1214-1225.

Renton, K., A. Salinas-Melgoza, M. Á. De Labra-Hernández, and S. M. de la Parra-Martínez. 2015. Resource requirements of parrots: nest site selectivity and dietary plasticity of Psittaciformes. Journal of Ornithology 156:73-90. https://doi. org/10.1007/s10336-015-1255-9

Reyes Macedo, G. 2007. Biología reproductiva de la guacamaya verde (Aramilitaris) en la Cañada oaxaqueña, dentro de la Reserva de la Biósfera Tehuacán-Cuicatlán. MS thesis, Instituto Politecnico Nacional.

Robinet, O., V. Bretagnolle, and M. Clout. 2003. Activity patterns, habitat use, foraging behaviour and food selection of the Ouvéa Parakeet (Eunymphicus cornutus uvaeensis). Emu - Austral Ornithology 103: 71-80. https://doi.org//10.1071/mu00032 
Roth, P. 1984. Repartição do habitat entre psitacídeos simpátricos no sul da Amazônia. Acta Amazonica 14:175-221. https://doi. org//10.1590/1809-43921984142221

Rycken, S., K. S. Warren, L. Yeap, B. Jackson, K. Riley, M. Page, R. Dawson, K. Smith, P. R. Mawson, and J. M. Shephard. 2019. Assessing integration of black cockatoos using behavioral change point analysis. Journal of Wildlife Management 83:334-342. https://doi.org/10.1002/jwmg.21609

Salinas-Melgoza, A. 2003. Dinámica espacio-temporal de individuos juveniles del loro corona lila (Amazona finshi) en el bosque seco de la costa de Jalisco. MS Thesis, Universidad Nacional Autónoma de México.

Salinas-Melgoza, A., and K. Renton. 2005. Seasonal variation in activity patterns of juvenile Lilac-crowned Parrots in tropical dry forest. Wilson Bulletin 117:291-295. https://doi.org/10.1676/04-096.1

Salinas-Melgoza, A., and K. Renton. 2007. Postfledging survival and development of juvenile Lilac-crowned Parrots. Journal of Wildlife Management 71:43-51. https://doi.org/10.2193/2005-646

Salinas-Melgoza, A., V. Salinas-Melgoza, and T. F. Wright. 2013. Behavioral plasticity of a threatened parrot in human-modified landscapes. Biological Conservation 159:303-312. https://doi. org/10.1016/j.biocon.2012.12.013

SAS Institute 2019. JMP®, Version 15. SAS Institute Inc., Cary, North Carolina, USA.

SERNANP. 2015. Listado oficial de las areas naturales protegidas. Available: http://old.sernanp.gob.pe/sernanp/archivos/ biblioteca/mapas/ListaAnps_11112015.pdf [Accessed 12 July 2019].

Silva, P. A. d. 2013. Ocorrência e forrageamento de psitacídeos em paisagem antropogênica do Noroeste Paulista, limítrofe MataAtlântica-Cerrado. PhD., Univ. Federal de Uberlândia.

Smith, G. T., and L. A. Moore. 1992. Patterns of movement in the Western Long-billed Corella Cacatua pastinator in the southwest of Western Australia. Emu - Austral Ornithology 92:19-27. https://doi.org/10.1071/MU9920019

Snyder, N. F. R., S. E. Koenig, J. Koschmann, H. A. Snyder, and T. B. Johnson. 1994. Thick-billed Parrot releases in Arizona. Condor 96:845-862. https://doi.org//10.2307/1369097

Soriano-Redondo, A., M. Acácio, A. M. A. Franco, B. H. Martins, F. Moreira, K. Rogerson, and I. Catry. 2020. Testing alternative methods for estimation of bird migration phenology from GPS tracking data. Ibis 162:581-588. https://doi. org//10.1111/ibi.12809

Stahala, C. 2008. Seasonal movements of the Bahama Parrot (Amazona leucocephala bahamensis) between pine and hardwood forests: implications for habitat conservation. Ornithologia Neotropical 19 (Suppl.):165-171.

Symes, C. T., and M. R. Perrin. 2003. Seasonal occurrence and local movements of the grey-headed (brown-necked) parrot Poicephalus fuscicollis suahelicus in southern Africa. African Journal of Ecology 41:299-305. https://doi.org//10.1111/ j.1365-2028.2003.00474.X

Tella, J. L., A. Baños, D. Hernández-Brito, A. Rojas, E. Pacífico, J. A. Díaz, M. Carrete, G. Blanco, and F. Hiraldo. 2015. Parrots as overlooked seed dispersers. Frontiers in Ecology and the Environment 13:338-339. https://doi.org/10.1890/1540-9295-13.6.338

Telonics 2015. Telonics Product Programmer, 2009 to 2015 versions. Telonics, Inc. Available at https://www.telonics.com/ software/tpp.php.

Tubelis, D. P. 2010. When a large reserve is not large enough to protect part of a population: Blue-and-yellow Macaws (Ara ararauna) in central Brazil. Biotemas 23:137-141. https://doi. org//10.5007/2175-7925.2010v23n3p137

Vaughan, C. 2019. Conservacion de la lapa roja (Ara macao) con manejo in situ en el Pacifico Central de Costa Rica. Revista de Ciencias Ambientales 53:166-188. https://doi.org/10.15359/ rca.53-2.10

Vaughan, C., N. Nemeth, and L. Marineros. 2003. Ecology and management of natural and artificial scarlet macaw (Ara macao) nest cavities in Costa Rica. Ornithologia Neotropical 14:381 - 396. [online] URL https://sora.unm.edu/node/119535

Vigo, G., M. Williams, and D. J. Brightsmith. 2011. Growth of Scarlet Macaw (Ara macao) chicks in southeastern Peru. Ornitologia Neotropical 22:143-153.

Vigo Trauco, G. 2020. Scarlet Macaw nesting ecology and behavior: Implications for conservation management. $\mathrm{PhD}$, Texas A\&M University.

Warton, B. J. 1989. Kernel methods for estimating the utilization distribution in home-range studies. Ecology 70:164-168. https:// doi.org/10.2307/1938423

Wheat, R. E., S. B. Lewis, Y. Wang, T. Levi, and C. C. Wilmers. 2017. To migrate, stay put, or wander? Varied movement strategies in bald eagles (Haliaeetus leucocephalus). Movement Ecology 5:9. https://doi.org/10.1186/s40462-017-0102-4

Wright, S. J., C. Carrasco, O. Calderón, and S. Paton. 1999. The El Niño southern oscillation, variable fruit production, and famine in a tropical forest. Ecology 80:1632-1647. https://doi. org//10.2307/176552
Editor-in-Chief: Alexander L.Bond Subject Editor: Katherine Renton

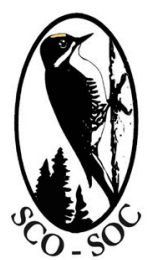

Sponsored by the Society of Canadian Ornithologists and Birds Canada

Parrainée par la Société des ornithologistes du Canada et Oiseaux Canada 


\section{SUPPLEMENTAL TABLES}

Table A1.1: Performance of the ARGOS satellite collars deployed on Scarlet and Blue-and-yellow Macaws in the lowlands of southeastern Peru from 2008 to 2016. The lifespan was calculated as the day of deployment until the last usable location. Useable locations were defined as locations with Argos user codes 3, 2, 1, or A (see text for details). Broadcast hours were calculated using the attach date, programmed duty cycle, and collar lifespan. The "Days with locations" is the number of days where the satellite received usable locations of the birds.

\begin{tabular}{lccc} 
& Mean & SD & N \\
\hline Collar lifespan (days) & 317 & 61 & 14 \\
Total usable locations & 261 & 106 & 14 \\
Broadcast days & 77 & 15 & 14 \\
Broadcast days $\geq$ 1 location & 69 & 17 & 14 \\
Broadcast days 0 locations & 8.3 & 9.1 & 14 \\
Locations per broadcast day & 3.4 & 1.4 & 14 \\
Broadcast hours & 577 & 145 & 14 \\
Locations per broadcast hour & 0.48 & 0.2 & 14 \\
Distinct dates with locations & 70 & 15 & 14 \\
\hline
\end{tabular}


Table A1.2: Breeding range parameters for Scarlet (SCMA) and Blue-and-yellow (BYMA) Macaws in the lowlands of southeastern Peru from 2008 to 2016. Part I. Deployment date is the date the collar was attached to the macaw. Two SCMA and all four BYMA were of unknown breeding status. Two SCMA and one BYMA did not leave the breeding range so have NA for data related to these movements. For our calculations, breeding season ended when the birds departed from their breeding areas (First departure from breeding) and began again when birds returned to their breeding range for the last time in anticipation of the following nesting season. The "First departure movement" is the distance from the nest (for Scarlet) or from the center of the breeding range (for Blue-andyellow) to the first location after the birds were detected outside their breeding range.

\begin{tabular}{|c|c|c|c|c|c|c|c|c|c|}
\hline Name & Year & Species & $\begin{array}{c}\text { Deployment } \\
\text { date }\end{array}$ & $\begin{array}{c}\text { First } \\
\text { usable } \\
\text { location }\end{array}$ & $\begin{array}{c}\text { Chick } \\
\text { fledge date }\end{array}$ & $\begin{array}{l}\text { Chicks } \\
\text { fledged }\end{array}$ & $\begin{array}{c}\text { First } \\
\text { departure } \\
\text { movement } \\
(\mathrm{km})\end{array}$ & $\begin{array}{l}\text { Last in } \\
\text { breeding } \\
\text { range before } \\
\text { depart }\end{array}$ & $\begin{array}{l}\text { Dates } \\
\text { visiting } \\
\text { back in } \\
\text { breeding } \\
\text { range }\end{array}$ \\
\hline Angeles & 2011 & SCMA & 24-Jan-11 & 30-Jan-11 & 6-Mar-11 & 1 & 37 & 26-Mar-11 & 0 \\
\hline Angeles & 2012 & SCMA & 24-Jan-12 & 30-Jan-12 & 6-Mar-12 & 2 & 11 & 8-Apr-12 & 2 \\
\hline Angeles & 2013 & SCMA & 5-Feb-13 & 12-Feb-13 & 14-Mar-13 & 1 & 43 & 4-Apr-13 & 10 \\
\hline Angeles & 2016 & SCMA & 26-Jan-16 & 8-Feb-16 & 25-Mar-16 & 1 & 41 & 1-Apr-16 & 28 \\
\hline Ceiba & 2012 & SCMA & 26-Feb-12 & 6-Mar-12 & 9-Mar-12 & 2 & 24 & 23-Mar-12 & 3 \\
\hline Franz & 2012 & SCMA & 20-Jan-12 & 6-Mar-12 & 17-Mar-12 & 1 & 22 & 27-Mar-12 & 21 \\
\hline Franz & 2013 & SCMA & 3-Feb-13 & 11-Feb-13 & 24-Feb-13 & 1 & 22 & 27-Mar-13 & 15 \\
\hline Hugo & 2013 & SCMA & 4-Feb-13 & $11-F e b-13$ & 21-Feb-13 & 2 & 24 & 27-Mar-13 & 8 \\
\hline Dany E & 2009 & SCMA & 2-Feb-09 & 3-Feb-09 & Unk & Unk & NA & NA & NA \\
\hline Wheezy & 2009 & SCMA & 2-Feb-09 & 6-Feb-09 & Unk & Unk & NA & NA & NA \\
\hline Charming & 2010 & BYMA & 14-Dec-09 & 14-Dec-09 & Unk & Unk & 64 & 7-Mar-10 & 1 \\
\hline Fuga & 2009 & BYMA & 21-Jan-09 & 30-Jan-09 & Unk & Unk & NA & NA & NA \\
\hline Libertad & 2008 & BYMA & 28-Jan-08 & 31-Jan-08 & Unk & Unk & 31 & 3-Mar-08 & 2 \\
\hline Tiny & 2008 & BYMA & 22-Jan-08 & 26-Jan-08 & Unk & Unk & 36 & 13-Мау-08 & 0 \\
\hline
\end{tabular}


Table A1.3: Non-breeding season ranging parameters for Scarlet (SCMA) and Blue-and-yellow (BYMA) Macaws tracked with Argos satellite transmitters in the lowlands of southeastern Peru from 2008 to 2016. The "Duration" is the number of days from the "First location" of the macaw outside its breeding range until the "Last location" before it returned to the breeding range for the last time. Useable locations are defined as all locations with Argos location codes of 3, 2, 1, or A. The Argos collars used did not broadcast every day and we did not receive locations on each broadcast day (see Table 1), so the "Days with locations" is the number of days where the system calculated usable locations of the birds. The "Distance from breeding range" was calculated as the distance of the bird from the nest (for Scarlets where nest locations were known) or from the center of the breeding season range (for Blue-andyellows where nesting status was not known). The two Scarlet and one Blue-and-yellow Macaws that did not use distinct nonbreeding ranges are not included in this table.

\begin{tabular}{|c|c|c|c|c|c|c|c|c|c|c|c|}
\hline \multirow[b]{2}{*}{ Name } & \multirow[b]{2}{*}{ Year } & \multirow[b]{2}{*}{ Species } & \multicolumn{2}{|c|}{$\begin{array}{c}\text { First in non-breeding } \\
\text { range }\end{array}$} & \multirow[b]{2}{*}{$\begin{array}{c}\text { Last } \\
\text { location }\end{array}$} & \multirow[b]{2}{*}{$\begin{array}{l}\text { Duration } \\
\text { non- } \\
\text { breeding } \\
\text { range } \\
\text { (days) }\end{array}$} & \multirow[b]{2}{*}{$\begin{array}{l}\text { Usable } \\
\text { locations }\end{array}$} & \multirow[b]{2}{*}{$\begin{array}{c}\text { Days } \\
\text { with } \\
\text { locations }\end{array}$} & \multicolumn{3}{|c|}{$\begin{array}{c}\text { Distance from breeding } \\
\text { range }(\mathrm{km})\end{array}$} \\
\hline & & & Date & $\begin{array}{c}\text { Days } \\
\text { post } \\
\text { fledging }\end{array}$ & & & & & Mean & Stdev & Max \\
\hline Angeles & 2011 & SCMA & 31-Mar-11 & 25 & 2-Aug-11 & 124 & 100 & 23 & 90 & 35 & 154 \\
\hline Angeles & 2012 & SCMA & 12-Apr-12 & 37 & 28-Jul-12 & 107 & 76 & 24 & 40 & 17 & 60 \\
\hline Angeles & 2013 & SCMA & 8-Apr-13 & 25 & 29-Aug-13 & 143 & 205 & 34 & 75 & 67 & 164 \\
\hline Angeles & 2016 & SCMA & 4-Apr-16 & 10 & 30-Jul-16 & 117 & 148 & 39 & 10 & 14 & 48 \\
\hline Ceiba & 2012 & SCMA & 27-Mar-12 & 18 & 8-Sep-12 & 165 & 150 & 40 & 43 & 14 & 77 \\
\hline Franz & 2012 & SCMA & 1-Apr-12 & 14 & 26-Aug-12 & 147 & 143 & 37 & 12 & 8.4 & 26 \\
\hline Franz & 2013 & SCMA & 31-Mar-13 & 35 & 9-Sep-13 & 162 & 182 & 38 & 27 & 27 & 80 \\
\hline Hugo & 2013 & SCMA & 31-Mar-13 & 38 & 4-Sep-13 & 157 & 202 & 37 & 13 & 7.2 & 26 \\
\hline Charming & 2010 & BYMA & 11-Mar-10 & Unk & 3-Sep-10 & 176 & 247 & 50 & 133 & 24 & 169 \\
\hline Libertad & 2008 & BYMA & 7-Mar-08 & Unk & 2-Sep-08 & 179 & 47 & 32 & 37 & 18 & 69 \\
\hline Tiny & 2008 & BYMA & 21-May-08 & Unk & 13-Jul-08 & 53 & 16 & 11 & 73 & 18 & 99 \\
\hline
\end{tabular}


Table A1.4: Breeding range parameters for Scarlet (SCMA) and Blue-and-yellow (BYMA) Macaws in the lowlands of southeastern Peru from 2008 to 2016. Part II. Two SCMA and all four BYMA were of unknown breeding status. Two SCMA and one BYMA did not leave the breeding range so have NA for data related to these movements. For our calculations, breeding season ended when the birds departed from their breeding areas and began again when birds returned to their breeding range for the last time in anticipation of the following nesting season ("Final return to breeding range"). The "Duration of breeding range" is the number of days from the first usable location to the first departure from the breeding range plus the "Final return to breeding range" to the "Last usable location." The Argos collars used did not broadcast every day and we did not receive locations on each broadcast day, so the "Days with locations" is the number of days where the system calculated usable locations of the birds.

\begin{tabular}{|c|c|c|c|c|c|c|c|c|}
\hline \multirow[b]{2}{*}{ Name } & \multirow[b]{2}{*}{ Year } & \multirow[b]{2}{*}{ Species } & \multicolumn{2}{|c|}{ Final return to breeding range } & \multirow[b]{2}{*}{$\begin{array}{l}\text { Date next } \\
\text { eggs laid }\end{array}$} & \multirow[b]{2}{*}{$\begin{array}{c}\text { Last } \\
\text { usable } \\
\text { location }\end{array}$} & \multirow[b]{2}{*}{$\begin{array}{c}\text { Days with } \\
\text { locations for } \\
\text { breeding range }\end{array}$} & \multirow[b]{2}{*}{$\begin{array}{c}\text { Duration of } \\
\text { breeding } \\
\text { range }\end{array}$} \\
\hline & & & Date & $\begin{array}{c}\text { Days before egg } \\
\text { laying }\end{array}$ & & & & \\
\hline Angeles & 2011 & SCMA & 3-Aug-11 & 100 & 11-Nov-11 & 15-Jan-12 & 46 & 225 \\
\hline Angeles & 2012 & SCMA & 29-Jul-12 & 117 & 23-Nov-12 & 21-Sep-12 & 26 & 127 \\
\hline Angeles & 2013 & SCMA & 30-Aug-13 & 81 & 19-Nov-13 & 7-Jan-14 & 34 & 185 \\
\hline Angeles & 2016 & SCMA & 30-Jul-16 & 125 & 2-Dec-16 & 16-Sep-16 & 33 & 104 \\
\hline Ceiba & 2012 & SCMA & 9-Sep-12 & $\dagger$ & & 31-Dec-12 & 21 & 134 \\
\hline Franz & 2012 & SCMA & 27-Aug-12 & 68 & 3-Nov-12 & 31-Dec-12 & 22 & 152 \\
\hline Franz & 2013 & SCMA & $10-$ Sep-13 & 51 & 31-Oct-13 & 2-Jan-14 & 33 & 162 \\
\hline Hugo & 2013 & SCMA & 5-Sep-13 & 72 & 16-Nov-13 & 17-Feb-14 & 44 & 213 \\
\hline Dany E & 2009 & SCMA & NA & NA & Unk & 2-Mar-10 & 102 & 392 \\
\hline Wheezy & 2009 & SCMA & NA & NA & Unk & 24-Sep-09 & 98 & 230 \\
\hline Charming & 2010 & BYMA & 7-Sep-10 & Unk & Unk & 5-Oct-10 & 15 & 115 \\
\hline Fuga & 2009 & BYMA & NA & NA & Unk & 26-Mar-10 & 76 & 420 \\
\hline Libertad & 2008 & BYMA & 5-Sep-08 & Unk & Unk & 23-Oct-08 & 23 & 84 \\
\hline Tiny & 2008 & BYMA & 22-Jul-08 & Unk & Unk & $27-O c t-08$ & 42 & 213 \\
\hline
\end{tabular}

$\uparrow$ This bird did not nest again until the subsequent season in October 2014. 


\section{Appendix 2}

Home ranges and data points of Scarlet and Blue-and-yellow Macaws in southeastern Peru. Each individual transmitter deployment is presented as a single figure ( $\mathrm{N}=14$ deployments on 10 different individual birds). Each figure contains the raw data points, the breeding season home range (100\% MCP) the non-breeding season home range (100\% MCP), the non-breeding season core area ( $70 \% \mathrm{KDE})$, and key landscape features (nest, clay licks, etc.). To give an idea of how the bird moved, we also provide an annotated discussion of the movements throughout the non-breeding range. All figures were created in ArcGIS 10.4 . 


\section{Scarlet Macaw: Dany 2009}
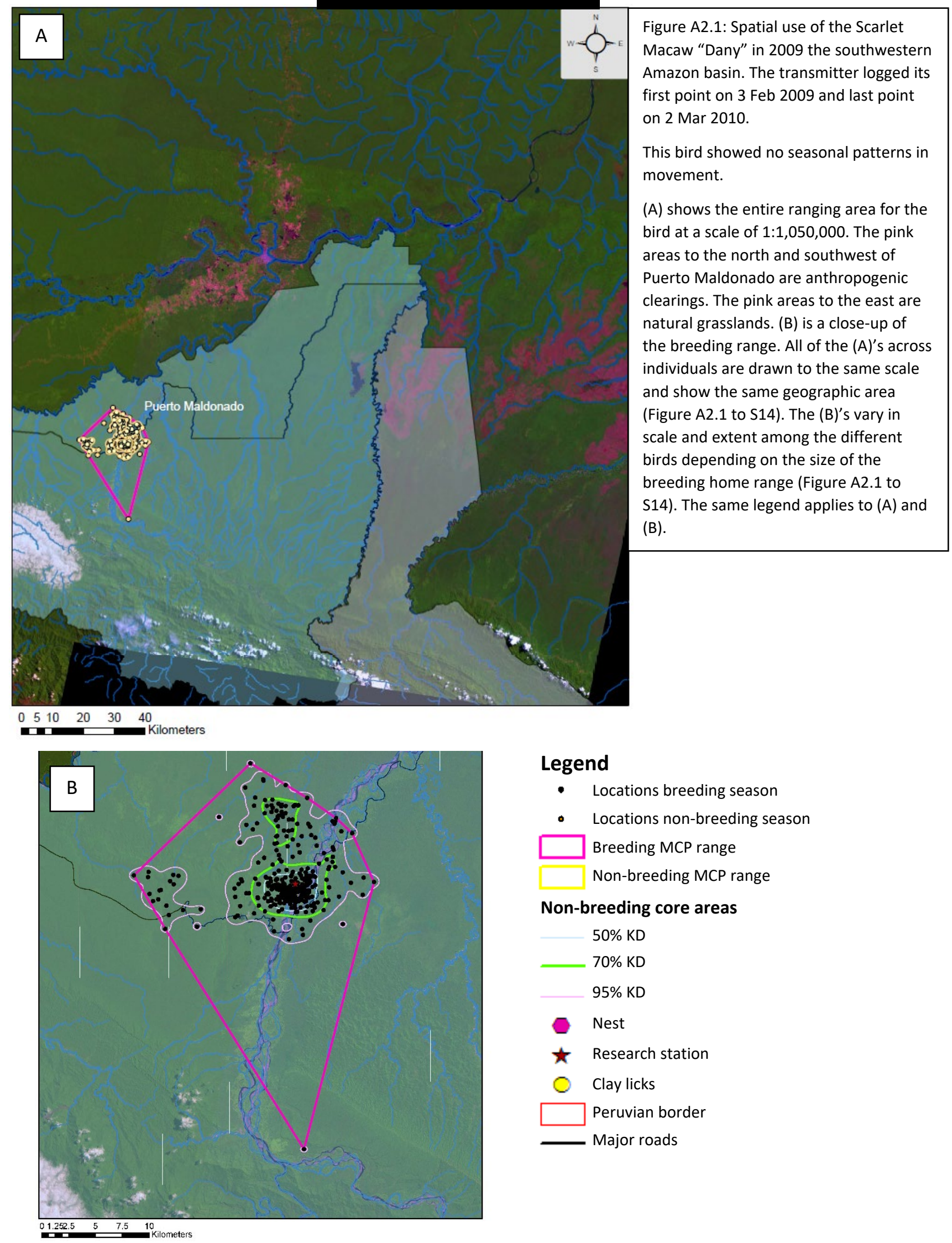

\section{Legend}

- Locations breeding season

- Locations non-breeding season

$\square$ Breeding MCP range

Non-breeding MCP range

\section{Non-breeding core areas}

\begin{tabular}{ll} 
& $50 \%$ KD \\
& $70 \%$ KD \\
& $95 \%$ KD \\
\hline$\quad$ Nest \\
$\star \quad$ Research station \\
$\bigcirc \quad$ Clay licks \\
$\square$ Peruvian border \\
\hline Major roads
\end{tabular}




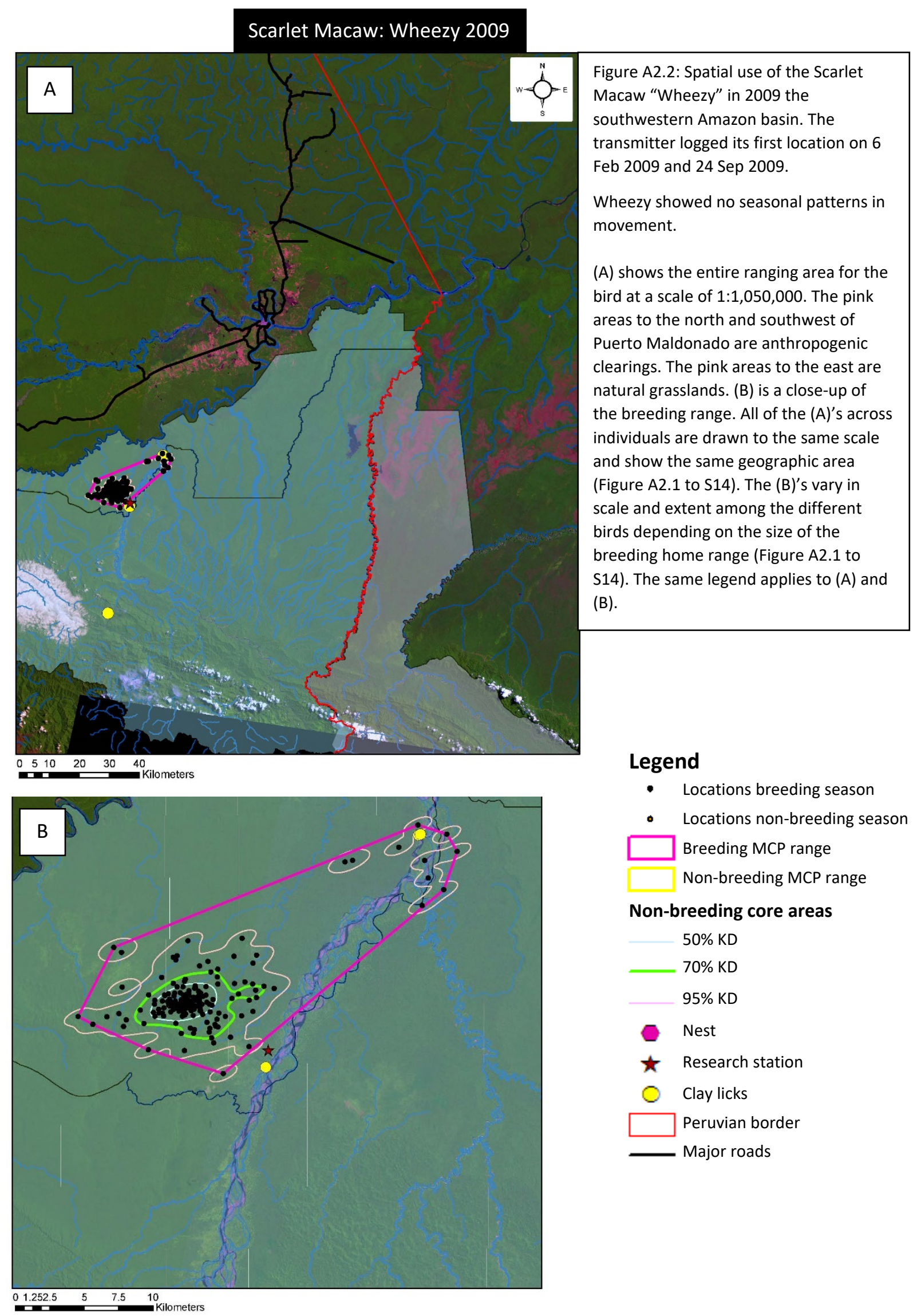




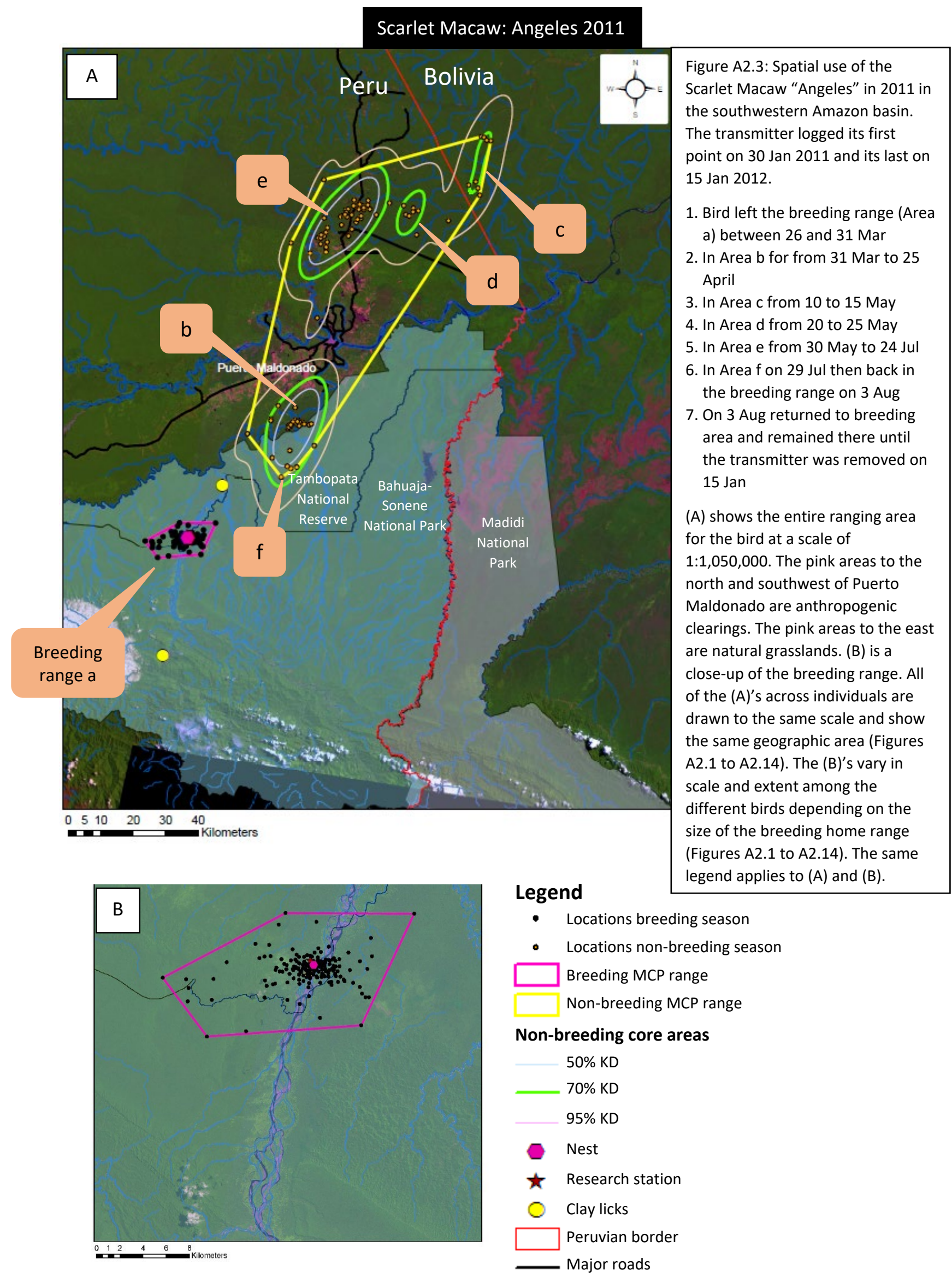




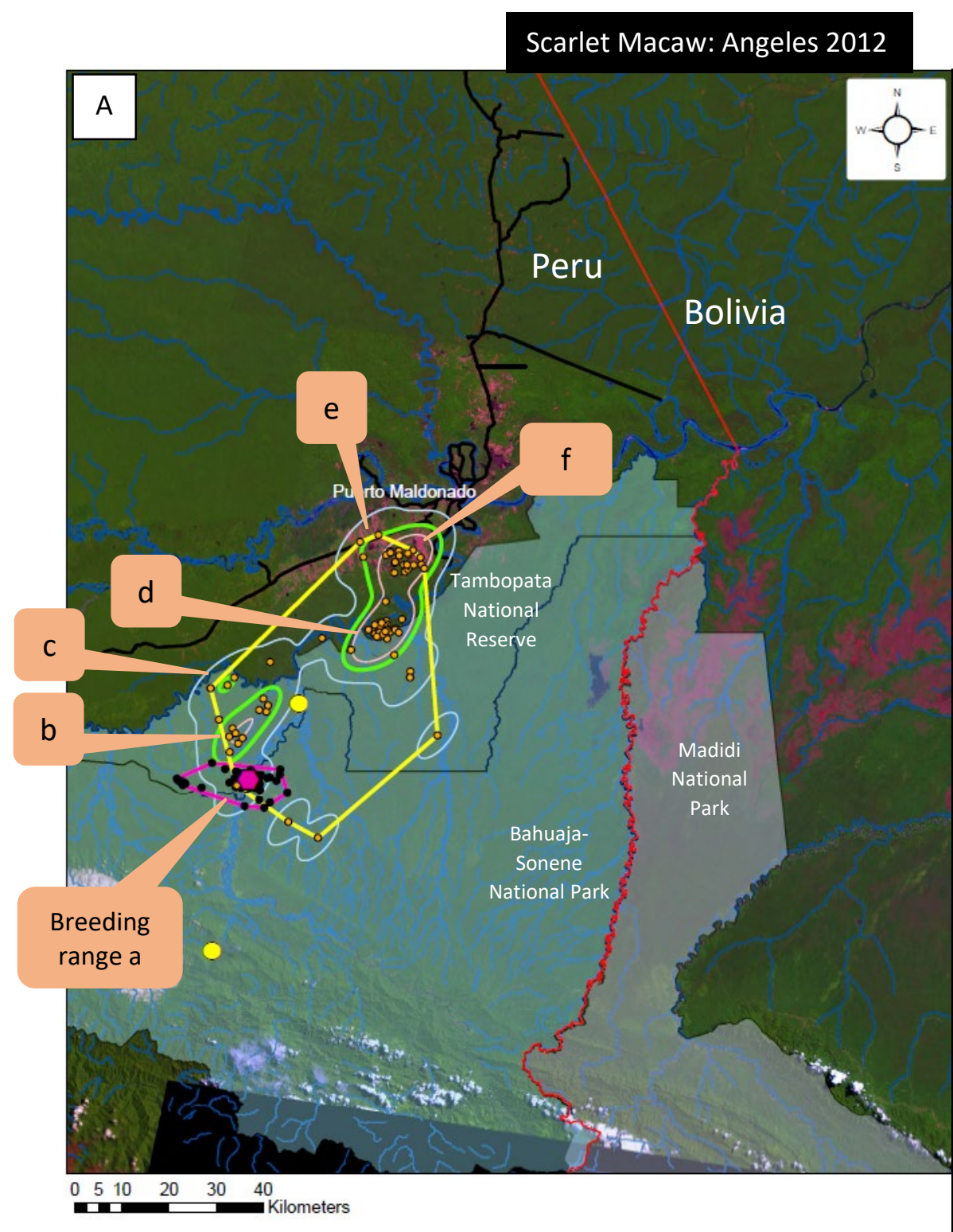

Figure A2.4: Spatial use of the Scarlet Macaw "Angeles" in 2012 the southwestern Amazon basin. The transmitter logged its first point on 30 Jan 2012 and its last on 21 Sep 2012.

1. Bird left the breeding range (Area a) between 8 and $12 \mathrm{Apr}$

2. In Area b on $12 \mathrm{Apr}$

3. In Area c from 16 to $20 \mathrm{Apr}$

4. In Area d from 20 to $28 \mathrm{Apr}$

5. Back in in Area b on 6 May

6. Back in Area d from 10 May to 7 Jun

7. On 11 Jun, the bird flew from Area d to the eastern and southern extremes of the range then to the breeding range

8. In Area e 15 Jun to $1 \mathrm{Jul}$

9. On 5 Jul bird moved from Area $c$ to the breeding range

10. In Area from 9 to $17 \mathrm{Jul}$

11. On $29 \mathrm{Jul}$ returned to breeding area and remained there until transmitter stopped working on 21 Sep

(A) shows the entire ranging area for the bird at a scale of 1:1,050,000. The pink areas to the north and southwest of Puerto Maldonado are anthropogenic clearings. The pink areas to the east are natural grasslands. (B) is a close-up of the breeding range. All of the $(A)$ 's across individuals are drawn to the same scale and show the same geographic area (Figures A2.1 to A2.14). The (B)'s vary in scale and extent among the different birds depending on the size of the breeding home range (Figures A2.1 TO A2.14). The same legend applies to (A)

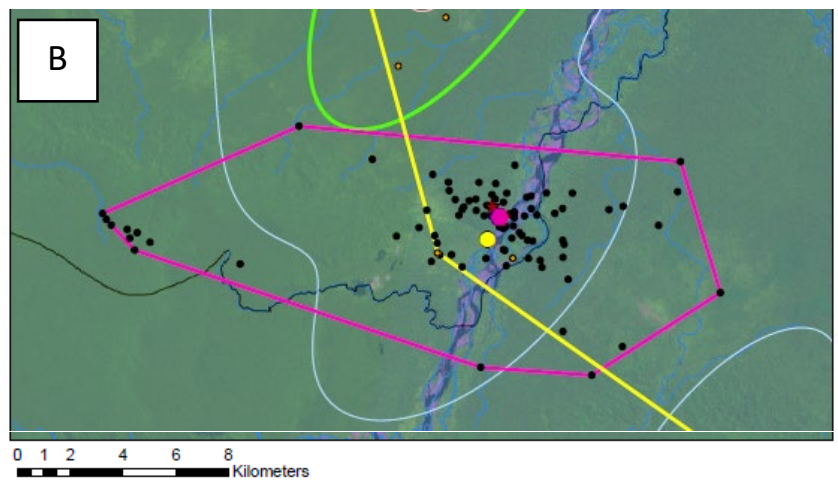

Legend

- Locations breeding season

- Locations non-breeding season

Breeding MCP range Non-breeding MCP range

Non-breeding core areas

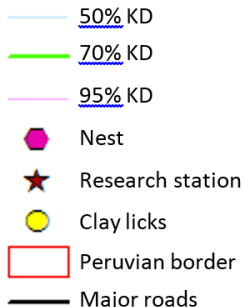




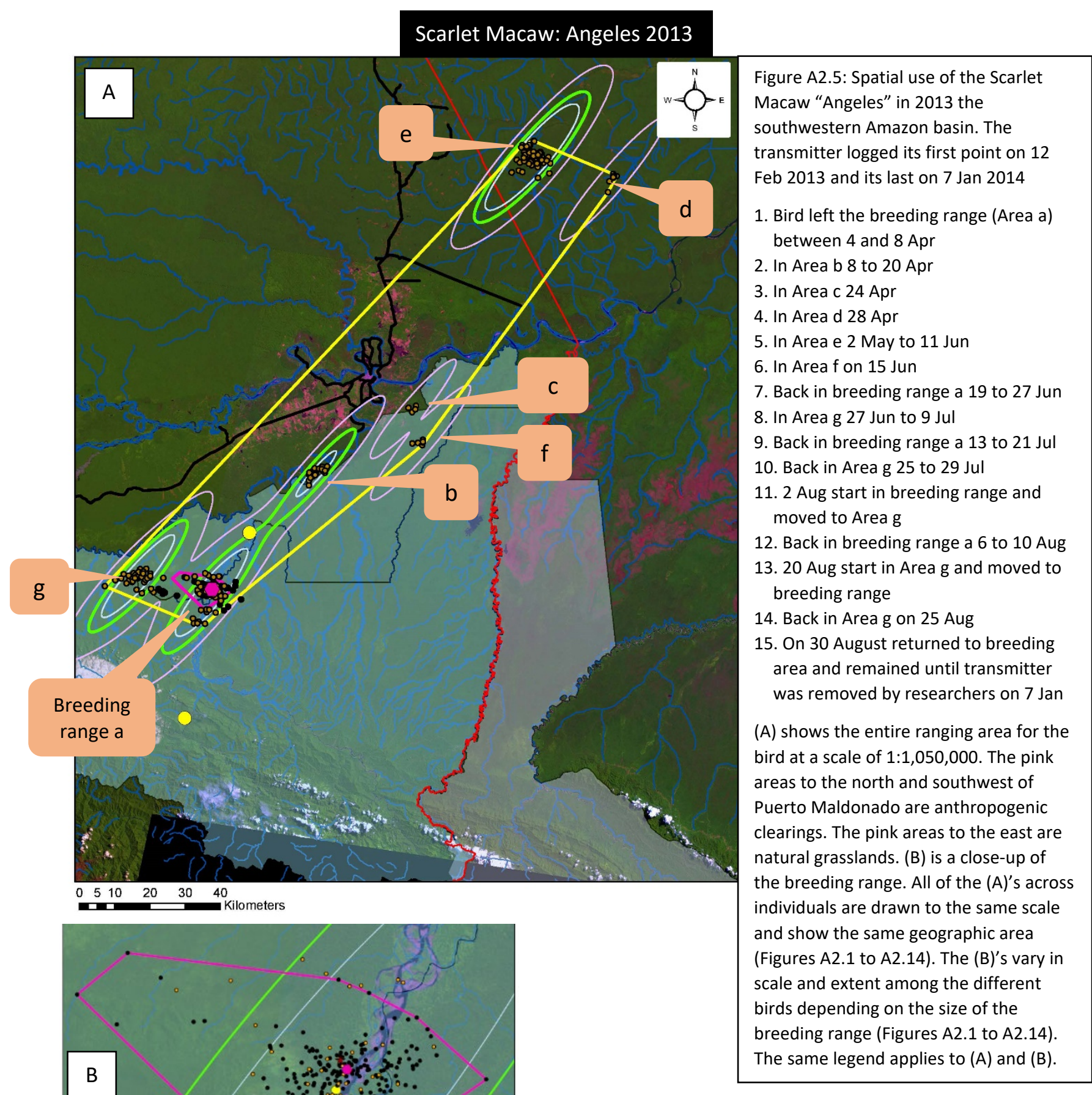

\section{Legend}

- Locations breeding season

- Locations non-breeding season

Breeding MCP range

Non-breeding MCP range

Non-breeding core areas

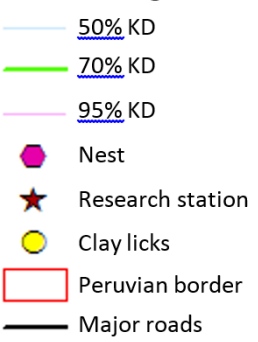




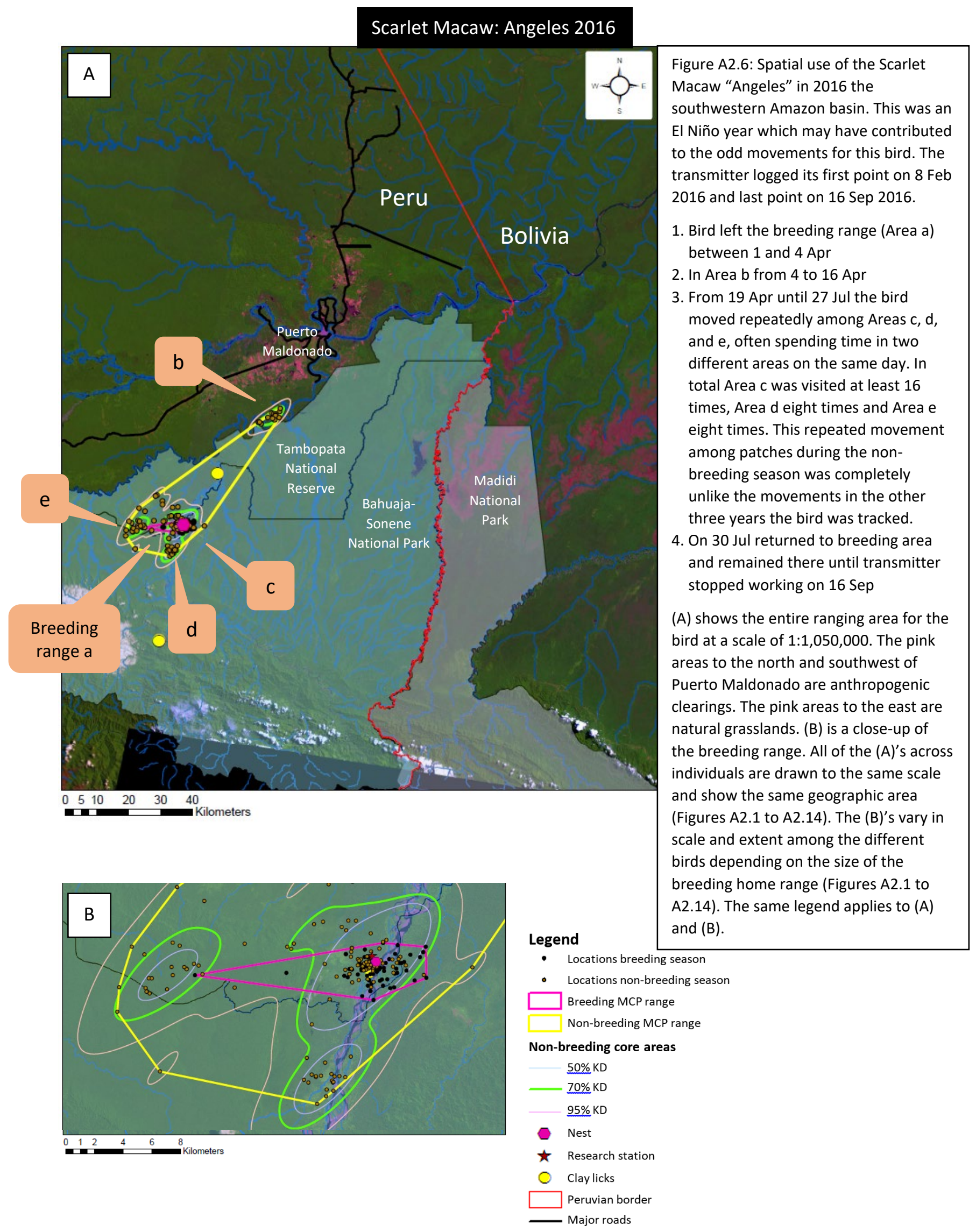




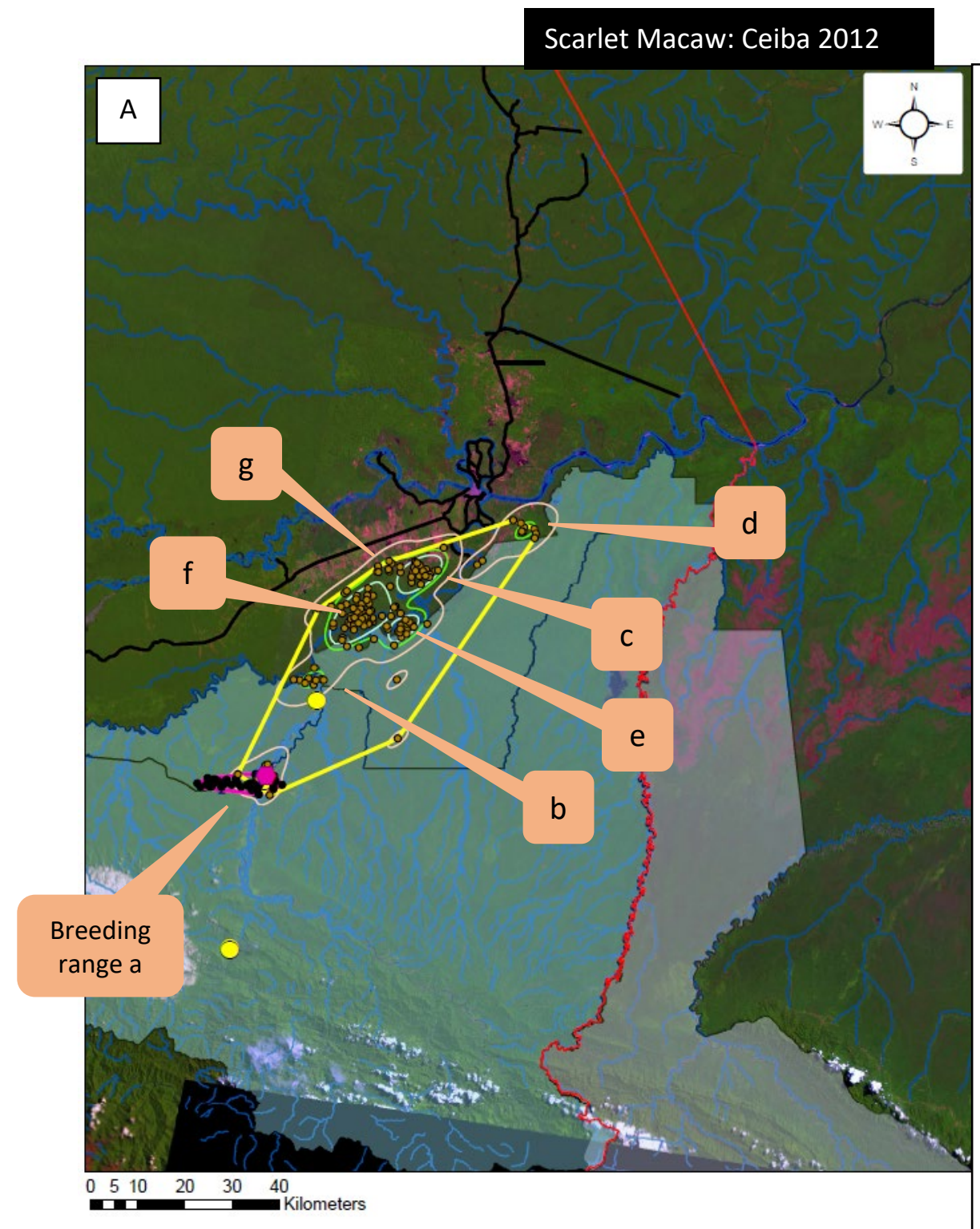

Figure A2.7: Spatial use of the Scarlet

Macaw "Ceiba" in 2012 in the

southwestern Amazon basin. The

transmitter logged its first location on 6

Mar 2012 and its last on 31 Dec 2012

1. Bird left the breeding range (Area a) between 23 and 27 Mar

2. In Area b 27 Mar to $4 \mathrm{Apr}$

3. In Area c 8 Apr to 10 May

4. In Area d 14 to 22 May

5. Back in breeding range a on 26 May

6. In Area e 30 May to 7 Jun

7. In Area f 11 to 15 Jun

8. In Area g 15 June to 19 Jun

9. Back in breeding range a on 23 Jun

10. Back in Area e on 27 Jun and moved to Area $f$

11. Stayed in Area $f 27$ Jun to 2 Sept

11. On 9 September returned to breeding area and remained there until transmitter stopped working.

(A) shows the entire ranging area for the bird at a scale of $1: 1,050,000$. The pink areas to the north and southwest of Puerto Maldonado are anthropogenic clearings. The pink areas to the east are natural grasslands. (B) is a close-up of the breeding range. All of the (A)'s across individuals are drawn to the same scale and show the same geographic area (Figures A2.1 to A2.14). The (B)'s vary in scale and extent among the different birds depending on the size of the breeding home range (Figures A2.1 to $A 2.14)$. The same legend applies to (A) and (B).

\section{Legend}

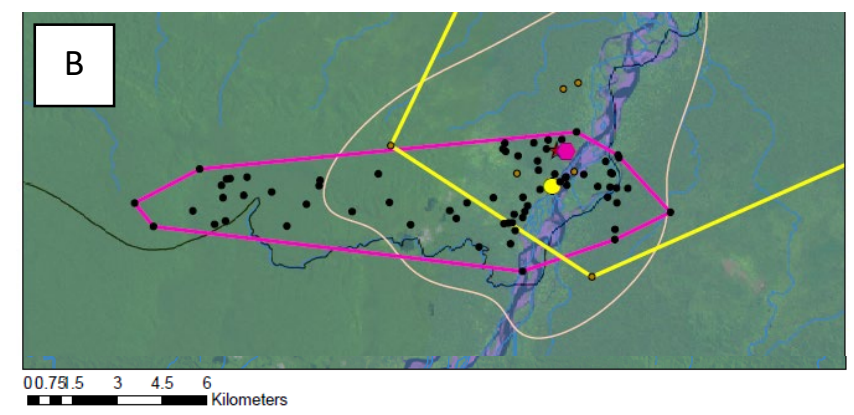

- Locations breeding season

- Locations non-breeding season

Breeding MCP range

Non-breeding MCP range

\section{Non-breeding core areas}

$50 \% \mathrm{KD}$

$70 \% \mathrm{KD}$

$95 \% \mathrm{KD}$

Nest

$\star$ Research station

Clay licks

Peruvian border

Major roads 


\section{Scarlet Macaw: Franz 2012}

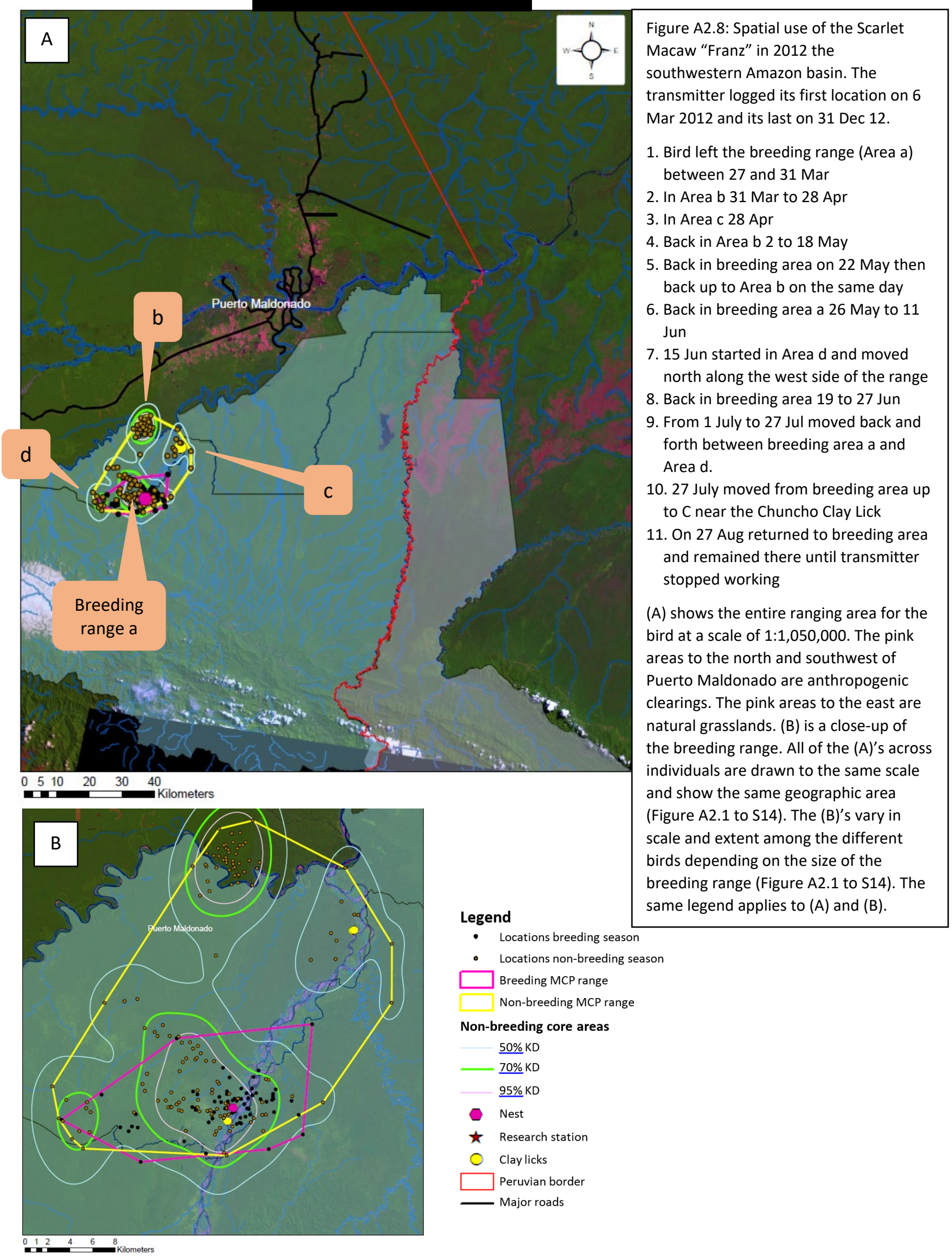



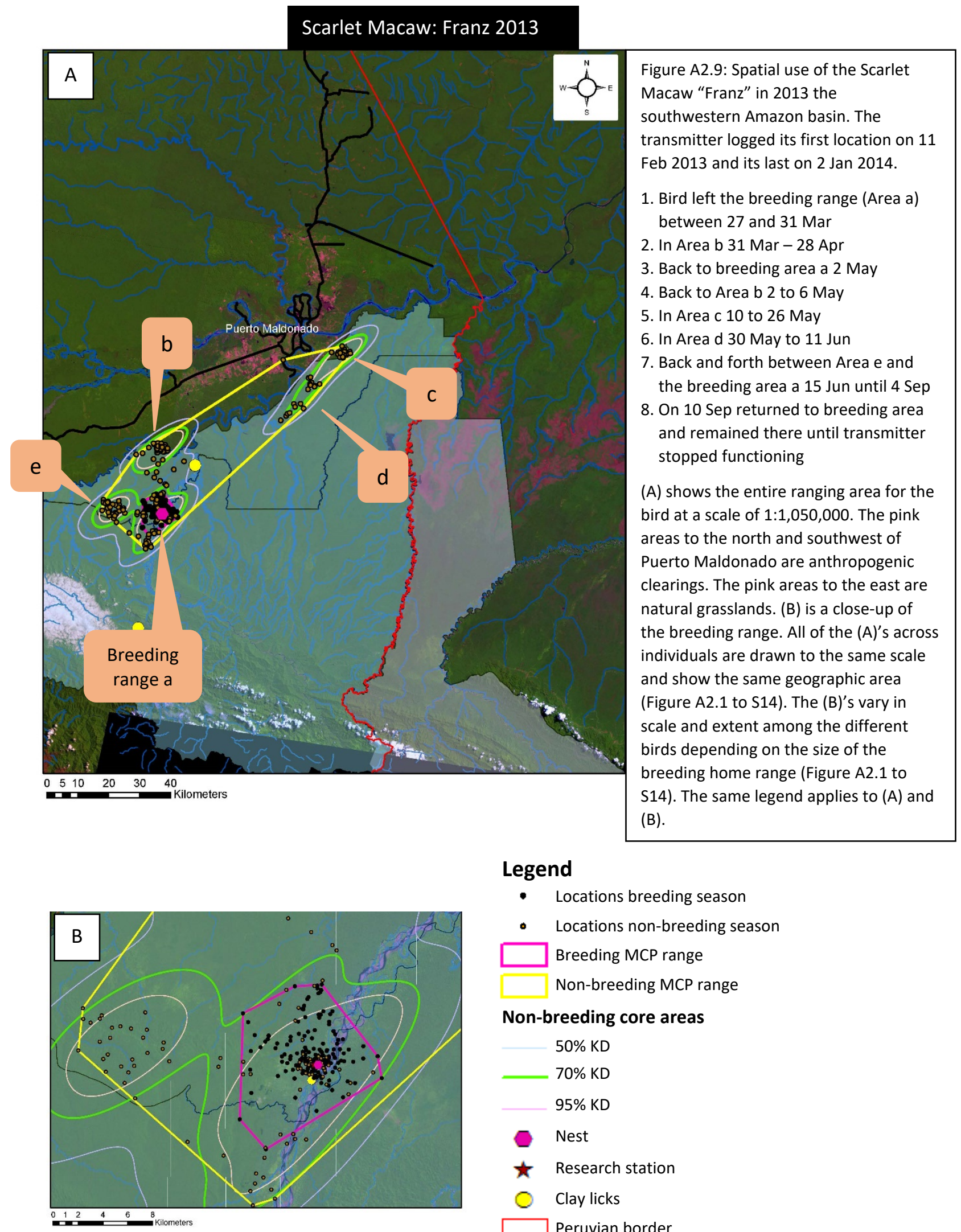

\section{Legend}

- Locations breeding season

- Locations non-breeding season

Breeding MCP range

Non-breeding MCP range

\section{Non-breeding core areas}

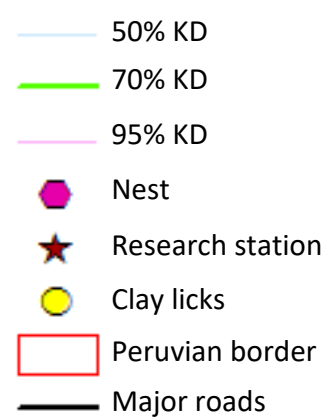



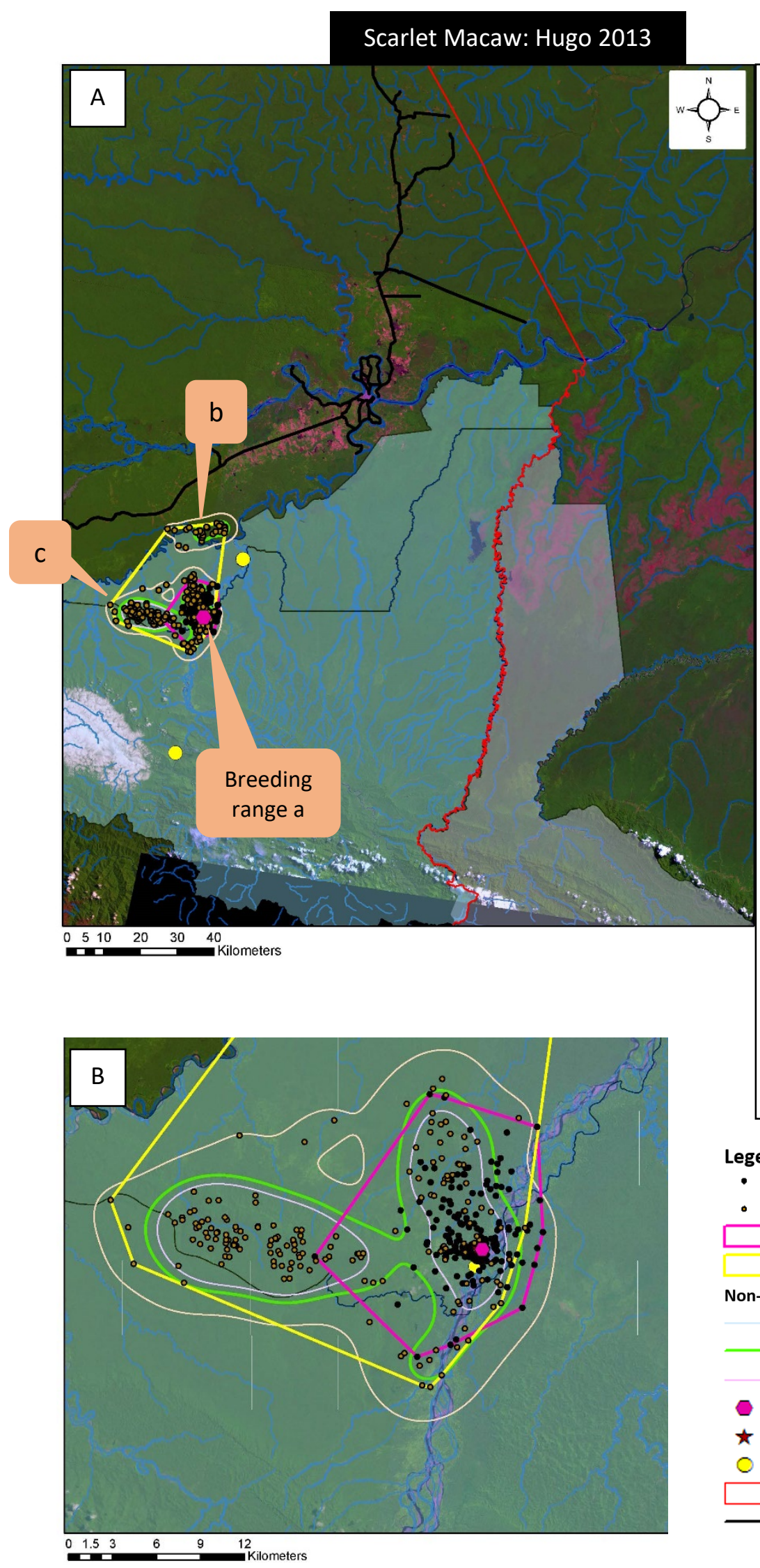

Figure A2.10: Spatial use of the Scarlet Macaw "Hugo" in 2013 the southwestern Amazon basin. The transmitter logged its first location on 11 Feb 2013 and its last on 17 Feb 2014.

1. Bird left the breeding range (Area a) between 27 and 31 Mar

2. In Area b $31 \mathrm{Mar}$

3. Back in breeding area 4 to $12 \mathrm{Apr}$

4. In Area c 16 Apr

5. 20 April moved from breeding area to b and stayed until $28 \mathrm{Apr}$

6. Back in Area c 2 to 26 May

7. Back in breeding area a 26 May to 3 June

8. Back in Area b 7-11 Jun

9. Back and forth between breeding range $a$ and $c$ from 15 Jun to 30 Aug

10. On 5 Sep returned to breeding area and remained there until transmitter stopped transmitting

(A) shows the entire ranging area for the bird at a scale of $1: 1,050,000$. The pink areas to the north and southwest of Puerto Maldonado are anthropogenic clearings. The pink areas to the east are natural grasslands. (B) is a close-up of the breeding range. All of the (A)'s across individuals are drawn to the same scale and show the same geographic area (Figure A2.1 to S14). The (B)'s vary in scale and extent among the different birds depending on the size of the breeding range (Figure $A 2.1$ to S14). The same legend applies to (A) and (B).

\section{Legend}

- Locations breeding season

- Locations non-breeding season

Breeding MCP range

Non-breeding MCP range

Non-breeding core areas
50\% KD
$-70 \% \mathrm{KD}$
95\% KD
- Nest
$\star$ Research station
Clay licks
Peruvian border Major roads 
Blue-and-yellow Macaw: Fuga 2009

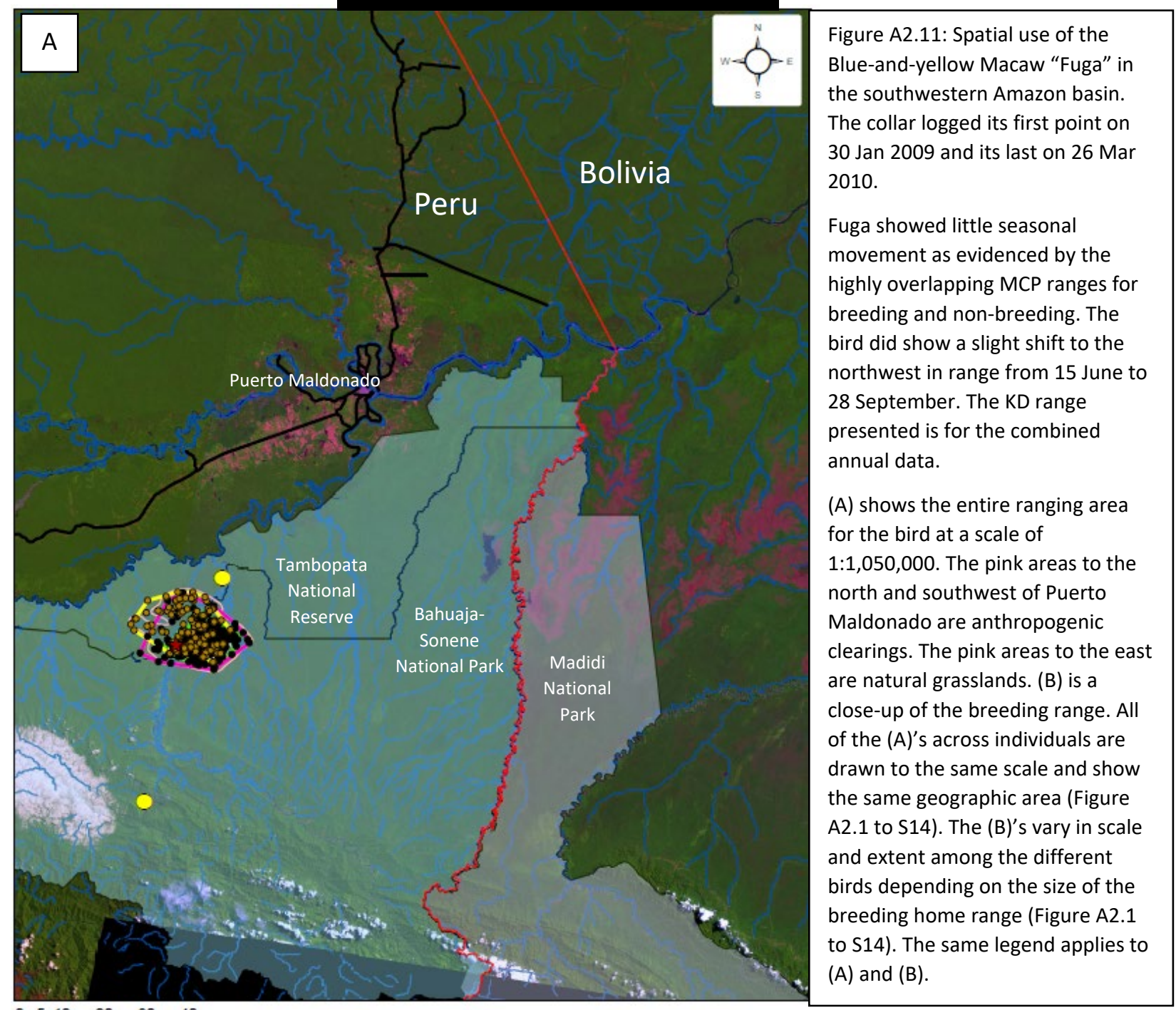

$\begin{array}{llllll}0 & 5 & 10 & 20 & 30 & 40\end{array}$

Kilometers

\section{Legend}

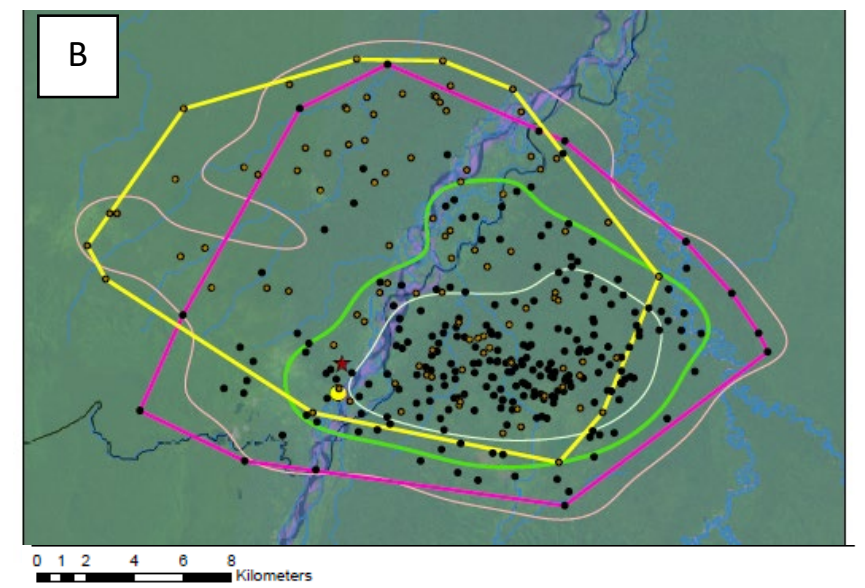

- Locations breeding season

- Locations non-breeding season

Breeding MCP range

Non-breeding MCP range

Non-breeding core areas

\begin{tabular}{ll} 
& $50 \% \mathrm{KD}$ \\
& $70 \% \mathrm{KD}$ \\
& $95 \% \mathrm{KD}$ \\
\hline$\quad$ Nest \\
$\star \quad$ Research station \\
$\bigcirc \quad$ Clay licks \\
$\square$ Peruvian border \\
$\square$ Major roads
\end{tabular}




\section{Blue-and-yellow Macaw: Tiny 2008}
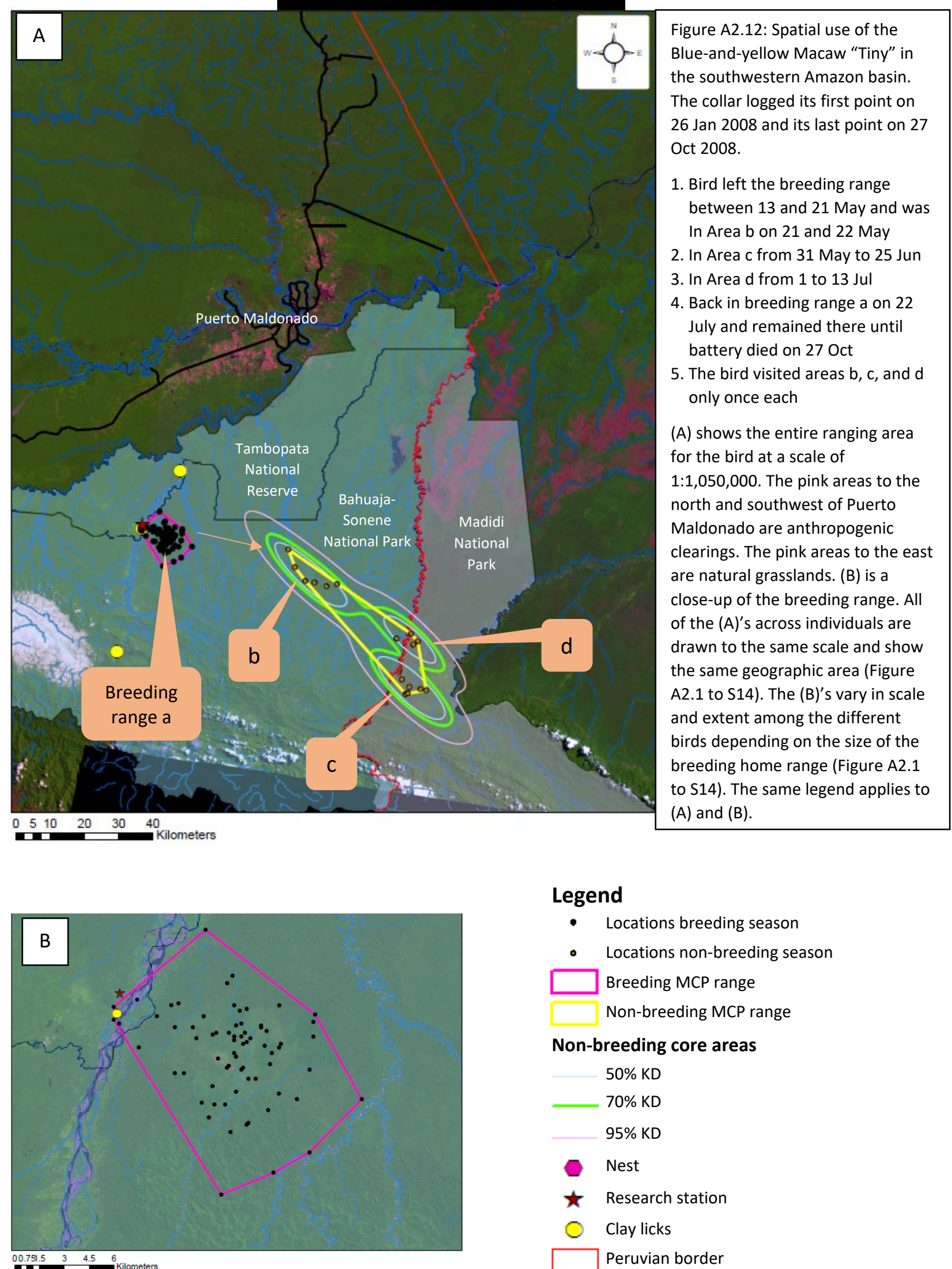

\section{Legend}

- Locations breeding season

- Locations non-breeding season

$\square$ Breeding MCP range

Non-breeding MCP range

\section{Non-breeding core areas}

\begin{tabular}{ll} 
& $50 \% \mathrm{KD}$ \\
- & $70 \% \mathrm{KD}$ \\
& $95 \% \mathrm{KD}$ \\
\hline$\quad$ Nest \\
$\star \quad$ Research station \\
$\bigcirc \quad$ Clay licks \\
$\square$ Peruvian border \\
\hline
\end{tabular}




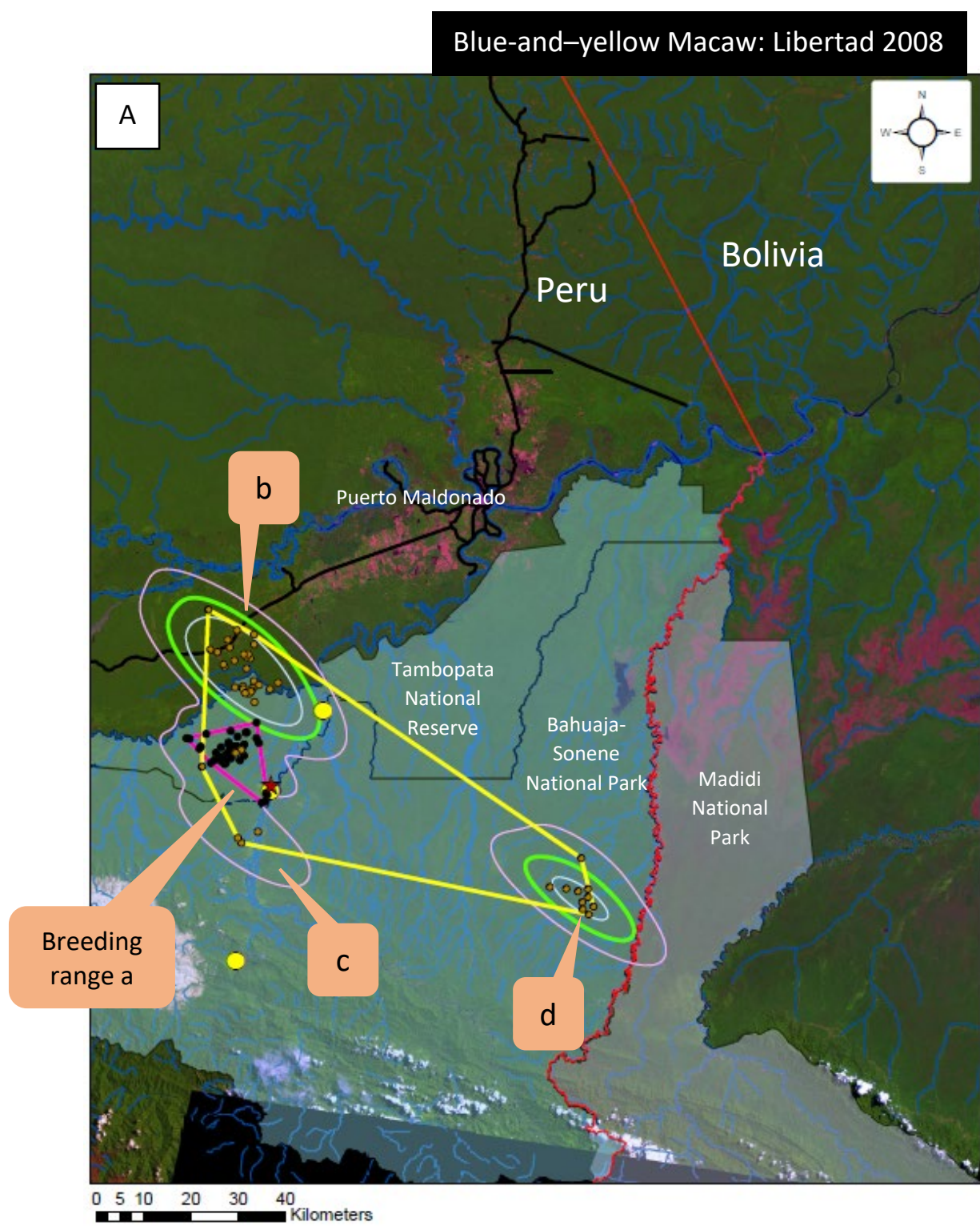

Figure A2.13: Spatial use of the Blueand-yellow Macaw "Libertad" in the southwestern Amazon basin. The collar logged its first point on 31 Jan 2008 and its last point on 23 Oct 2008.

1. Bird left the breeding range between 3 and 7 Mar and was In Area $b$ for one broadcast day

2. In Area c on 15 Mar

3. Back in Area b from 27 Mar to 12 Apr

4. Back in breeding range a on 16 and $20 \mathrm{Apr}$

5. 28 Apr to 17 Jun in Area d

6. 26 June to 2 Sep back in Area $b$

7. 6 September back in breeding range a where it remained until the battery died on 23 Oct

(A) shows the entire ranging area for the bird at a scale of $1: 1,050,000$. The pink areas to the north and southwest of Puerto Maldonado are anthropogenic clearings. The pink areas to the east are natural grasslands. (B) is a close-up of the breeding range. All of the $(A)$ 's across individuals are drawn to the same scale and show the same geographic area (Figure A2.1 to S14). The (B)'s vary in scale and extent among the different birds depending on the size of the breeding home range (Figure A2.1 to S14). The same legend applies to (A) and (B).

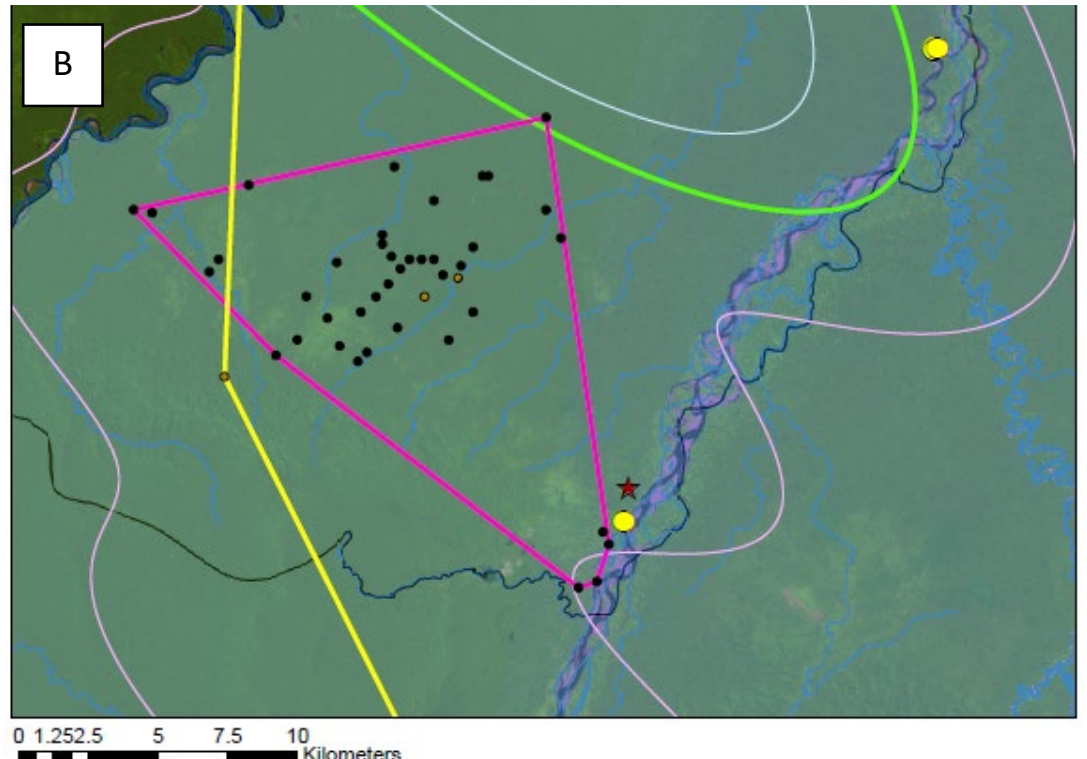

\section{Legend}

- Locations breeding season

- Locations non-breeding season

Non-breeding MCP range

\section{Non-breeding core areas}

\begin{tabular}{ll} 
& $50 \% \mathrm{KD}$ \\
- & $70 \% \mathrm{KD}$ \\
- & $95 \% \mathrm{KD}$ \\
$-\quad$ Nest \\
$\star \quad$ Research station \\
$\square \quad$ Clay licks \\
$\square$ Peruvian border \\
\hline
\end{tabular}




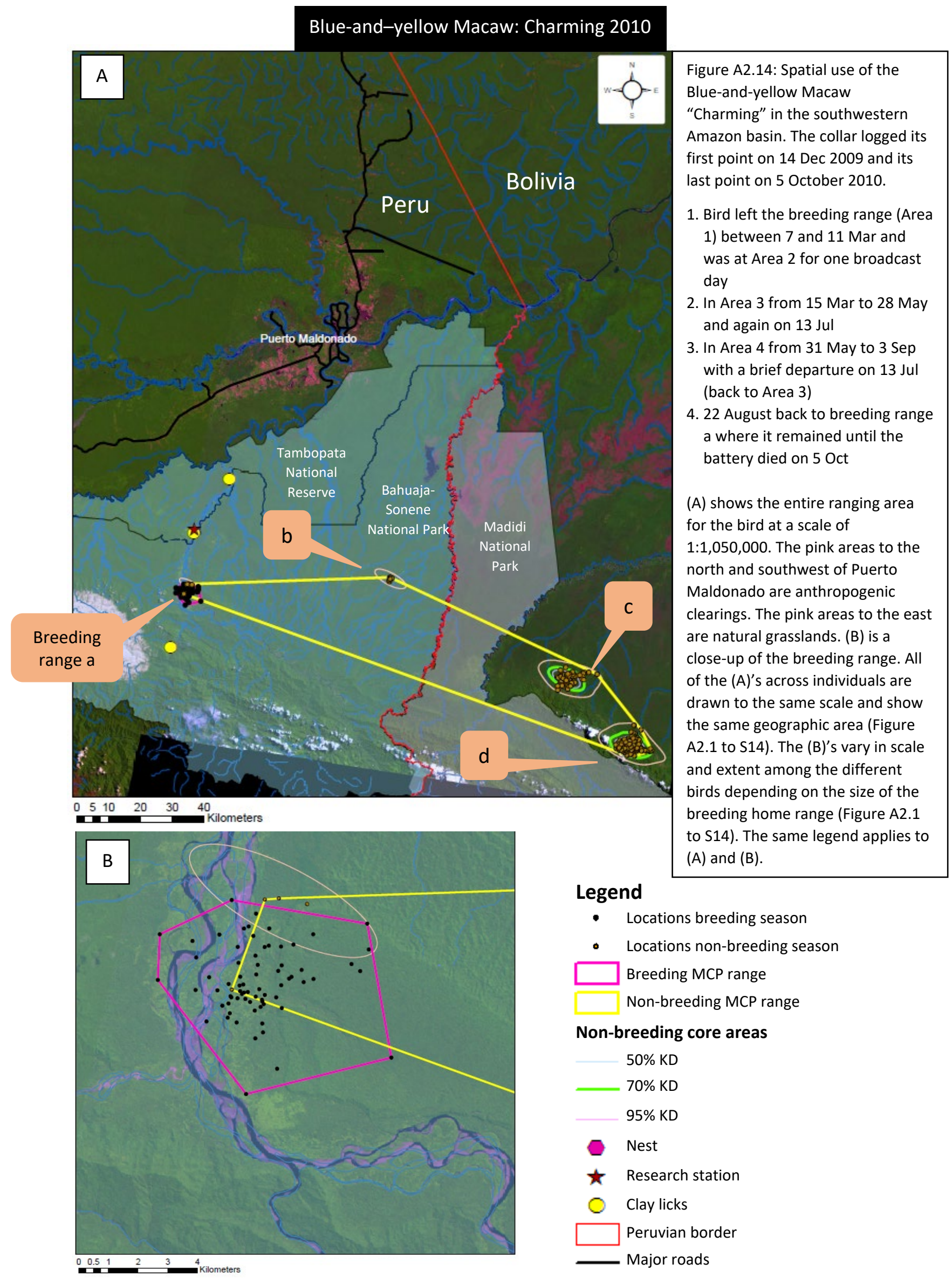

